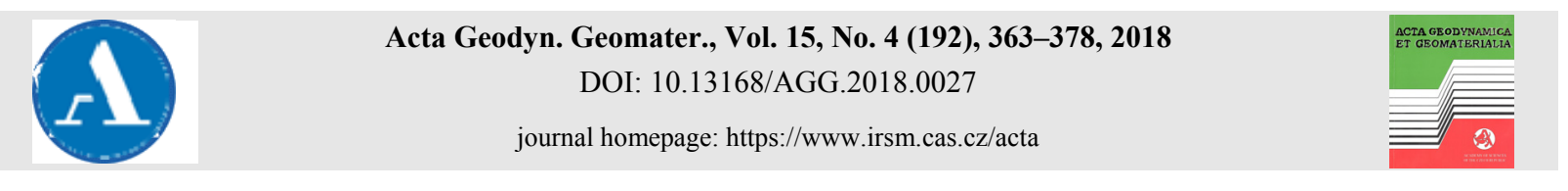

ORIGINAL PAPER

\title{
IGS08.ATX TO IGS14.ATX CHANGE DEPENDENT DIFFERENCES IN A GNSS-DERIVED POSITION TIME SERIES
}

\author{
Karol DAWIDOWICZ \\ Faculty of Geodesy, Geospatial and Civil Engineering, University of Warmia and Mazury \\ ul. Oczpowskiego 1, 10-719 Olsztyn, Poland \\ *Corresponding author's e-mail: karol.dawidowicz@uwm.edu.pl
}

\begin{tabular}{l} 
ARTICLE INFO \\
\hline Article history: \\
Received 8 August 2018 \\
Accepted 16 November 2018 \\
Available online 26 November 2018 \\
\hline Keywords: \\
GNSS \\
PPP \\
igs08.atx \\
igs14.atx \\
PVC \\
PCC \\
Position time series
\end{tabular}

\begin{abstract}
Changes in the position of the GNSS receiver antenna phase centre are still one of the dominant error sources associated with the measuring station. The preferred method of solving the problem is modeling antenna phase centre variations (PCV). Such models are available in igs05.atx, igs08.atx or igs14.atx files, among others. Due to different methods of antenna calibration (chamber calibration, relative field calibration, absolute field calibration) and different types of models (mean, individual), depending on the GNSS observation processing product used, there may occure differences in the estimated parameters, including station coordinates.

In this paper, the results of GNSS observation processing using the models included in the igs08.atx and igs14.atx files for 12 EPN and ASG-EUPOS stations were analysed, both for daily and sub-daily time series of PPP solutions. The obtained results show that switching from the igs08.atx to igs14.atx (for the selected stations) induces differences in the vertical component, reaching up to $\pm 3 \mathrm{~mm}$.
\end{abstract}

\section{INTRODUCTION}

Changes in the position of the GNSS receiver antenna phase centre are still one of the dominant error sources associated with the measuring station. The amplitude of these changes can reach several centimetres. The effect is especially visible in the function of the elevation angle of the incoming signal, although the azimuth may also have a significant impact, especially for very long baselines. Ignoring changes in the antenna phase centre position can lead to significant errors in determining the estimated parameters, especially the vertical position component (Rothacher and Mader, 1996; Mader, 1999; HofmannWellenhof et al., 2001; Kersten and Schön, 2016).

The preferred method of solving the problem is modeling antenna phase centre variations (PCV). At present, there are three main methods of modeling changes in the position of the phase centre of the GNSS receiver antennas:

- measurements in the anechoic chamber,

- relative field calibration,

- $\quad$ absolute field calibration.

Chronologically, the first developed method of antenna calibration was calibration in the anechoic chamber, where the phase of the transmitted and received GNSS signal is compared in the network analyser. The main advantage of this method is that it provides very high efficiency and the same conditions for all calibrated antennas. The disadvantage is that the test signal is not the same as the real GNSS signal (Görres et al., 2006; Zeimetz and Kuhlman, 2008).

The first method of field calibration is the socalled "relative calibration" (Rothacher and Mader, 1996; Mader, 1999). This method is based on the assumption that the phase centre variations of the reference antenna (Allen Osborne's AOAD / M_T antenna) are equal zero. Phase centre corrections (PCC) of the calibrated antenna are determined using single differences of GNSS observations, based on a comparison of the phase of the signal observed in a particular measurement epoch to the phase of the signal determined on the basis of the mean phase centre position (MPC) and modeled using the fourth degree polynomial in the elevation function (Mader, 1999). In this method, obtaining PCC for low elevation angles is practically impossible, due to high noise and the stronger multipath effect of such signals. It should be noted, that the first "full" (PCO and elevation dependent PCV) introduced models in GNSS measurements were based on this technique.

The approach known as the absolute field calibration of GNSS antennas was developed by Institut für Erdmessung (University of Hannover) and the Geo++ company (Wübben et al., 1996). The basic aim of this method is to estimate the PCC regardless of the type of used reference antenna. An additional 
advantage is the almost full elimination of the multipath effect. This method allows PCC estimation to the zero degree of elevation. Like in the relative calibration procedure, PCC is determined on the basis of single differences of GNSS observation, and the final shape of phase characteristics is determined using spherical harmonics. The absolute PCC models of receiver antennas have been supplemented by similar models for satellite antennas (Zhu et al., 2003; Schmid et al., 2007).

The advantage of both field methods is that they are based on real GNSS signals received in the natural environment.

Additionally, for antennas that do not have models directly from absolute field calibration, such models can be created by converting from relative ones. In this approach, the results obtained from the relative calibration are added to the results of the absolute field calibration of the AOAD/M_T antenna. Generally, in practical applications, we can talk about three types of PCC models for receiver antennas:

- relative PCC models (from relative field calibration),

- absolute PCC models (converted from relative field calibration),

- absolute PCC models (from absolute field calibration or anechoic chamber calibration).

The PCC models of the receivers' antennas included in the igs05.atx (introduced on 5 November, 2006), igs08.atx (introduced on 17 April, 2011) or igs14.atx (introduced on 29 January, 2017) files are mean models created from available individual antenna calibration results. In this method, several antennas from the same production line are calibrated several times. The results obtained for several antennas of the same type are then averaged and form a mean model. This approach assumes that PCV antennas of the same type can be represented with sufficient accuracy by such mean values.

In addition to the mean models, the stations of permanent networks realizing GNSS measurements with the highest precision, e.g. the EUREF Permanent GNSS Network (EPN) and the Active Geodetic Network (ASG-EUPOS) used the so-called individual models that refer to a specific antenna. In individual calibration, one particular antenna is calibrated several times. The results from these calibrations are then used for the PCC model creation for this particular antenna.

The switching from relative to absolute models has led to a significant improvement in GNSS solution results. Only GNSS measurements based on absolute models do not generate systematic shifts in combination with other space techniques (e.g. SLR, VLBI). These shifts significantly decreased when relative models were replaced by absolute ones (Völksen, 2006; Stępniak et al., 2015). The update of antenna calibration models from igs05.atx to igs.08.atx was another step in the improvement of
PCC models (Baire et al., 2011, 2013). The use of individual calibration also brought noticeable changes in the position time series. In Dawidowicz (2018) it was found that the position offsets resulting from the use of individual calibrations instead of type-mean igs08.atx calibrations can reach up to $5 \mathrm{~mm}$ in the Up component, while in the horizontal components the offsets generally remain below $1 \mathrm{~mm}$. The results prove that that a type mean calibration cannot correctly represents the antenna PCC for all antenna/radome types.

The newest realization of the International Terrestrial Reference System is ITRF2014. Each subsequent realization of ITRF is considered as a refinement of the previous one. In this case, for the first time in history, ITRF was generated with the modeling of a non-linear station's movements, including seasonal (annual and semi-annual) station position signals and post-seismic deformation for objects that have suffered major earthquakes (Altamimi et al., 2016; Figurski and Nykiel, 2017). In parallel with the introduction of ITRF2014, updated PCC models of both receivers and satellites (igs14.atx) were released.

In the paper, the differences in position time series, obtained by comparing the results of GNSS solutions using the igs08.atx and igs14.atx PCC models, were analysed. The time series of coordinates were derived from the GNSS observations processing using the precise point positioning (PPP) technique. The advantages and limitations of PPP positioning have been described, among others, in Kouba and Héroux (2001), El-Mowafy (2011), Rizos et al. (2012), Alkan and Öcalan (2013), Yigit et al. (2013) and Mohammed et al. (2016).

Similar investigations were conducted by Figurski and Nykiel (2017). However, their results were obtained based on the Bernese double difference GNSS processing. In presented work the processing were made using PPP method. Additionally presented work focuses also on GPS-only, GLONASS-only and GNSS solution differences as well as on antenna type dependent differences in position time series.

\section{METHODOLOGY}

GPS/GLONASS observations recorded on twelve selected EPN and ASG-EUPOS stations, with representative for these networks antenna types, were used for analyses. One of the main tasks of the EPN is to ensure the implementation of the European Terrestrial Reference System 89 (ETRS89). ASGEUPOS stations, on the other hand, constitute the primary horizontal and vertical extensive geodetic network in Poland (Bosy et al., 2008; Figurski et al., 2010; Dawidowicz et al., 2014; Paziewski et al., 2014).

A set of observations covering 2016 and 2017 was used for the analyses (for sub-daily analyses: 19 January - 7 February, 2017). The hardware installed at chosen stations is presented in Table 1. 
Table 1 Characteristics of the stations' hardware.

\begin{tabular}{clccccc}
\hline No. & Station & Network & \multicolumn{2}{c}{ Hardware } & $\begin{array}{c}\text { No. of calibrated } \\
\text { antennas in atx file: }\end{array}$ \\
\cline { 3 - 6 } & & & Antenna type & Receiver type & igs08 & igs14 \\
\cline { 3 - 6 } 1 & BORJ & EPN & LEIAR25.R3 LEIT & JAVAD TRE_3 DELTA & 5 & 28 \\
2 & DOUR & EPN & LEIAR25.R3 NONE & SEPT POLARX4 & 5 & 20 \\
3 & LEJI & EPN & LEIAR25.R3 LEIT & JAVAD TRE_G3TH DELTA & 5 & 28 \\
4 & WARN & EPN & LEIAR25.R3 LEIT & JAVAD TRE_G3TH DELTA & 5 & 28 \\
5 & DILL & EPN & LEIAR25.R4 LEIT & LEICA GR25 & 5 & 35 \\
6 & EUSK & EPN & LEIAR25.R4 LEIT & LEICA GR25 & 5 & 35 \\
7 & HELG & EPN & LEIAR25.R4 LEIT & JAVAD TRE_G3TH DELTA & 5 & 35 \\
8 & ISTA & EPN & LEIAR25.R4 LEIT* & LEICA GR25* & 5 & 35 \\
9 & BYDG & ASG-EUPOS & TRM59900.00 SCIS & TRIMBLE NETR9 & 5 & 5 \\
10 & GWWL & ASG-EUPOS & TRM59900.00 SCIS & TRIMBLE NETR9 & 5 & 5 \\
11 & REDZ & ASG-EUPOS & TRM59900.00 SCIS & TRIMBLE NETR9 & 5 & 5 \\
12 & ZYWI & ASG-EUPOS & TRM59900.00 SCIS & TRIMBLE NETR9 & 5 & 5 \\
\hline
\end{tabular}

* from 9.05.2016

In PPP measurement technique, it is necessary to use precise orbits and satellite clocks as well as implement a number of other models and corrections. In processing using the scientific software package NAvigation Package for Earth Orbiting Satellites (NAPEOS) ver. 3.3.1 (Springer, 2009), a standard processing strategy was used with the general weighted least squares parameter estimation method. The more important processing options include:

- precise orbit and clock information: from European Space Agency (ESA),

- elevation mask: $10^{\circ}$,

- weighting function: $1 / \cos (\mathrm{z})$ where $z$ is an elevation angle,

- $\quad$ a priori zenith path delays (ZPDs): computed with the formula of Saastamoinen with the use the Global Pressure and Temperature (GPT) model,

- zenith path delays mapping into slant delays: using the Vienna Mapping Function 1 (VMF1) (Boehm et al., 2006),

- elimination of the Ionosphere effect: first-order effect elimination using ionosphere-free linear combination; higher-order effects were not corrected.

The computations were based on the two frequencies float ambiguity solution.

The comparisons were made for both daily and sub-daily (30-minute) time series of PPP solutions performed in three variants: using GPS-only observations, using GLONASS-only observations, and combined GNSS processing (GPS+GLONASS).

In each variant two parallel PPP processing were performed, leaving all options the same, except files containing antenna calibration models:

- PPP processing using igs08_1842.atx,

- PPP processing using igs14_1934.atx,

- calculation of differences.
Generally it is assumed that all error sources can be considered identical in both compared solutions and the differences in the final results are caused by differences in antenna calibration models (Baire et al., 2013). However, if the IGS14 model and ephemeris with clocks expressed in IGb08 are used, a systematic error occurred. The error results from the fact that the IGb08 model was used to develop the ephemeris and clocks. An attempt to estimate the impact of mentioned above systematic error ("ephemeris and clocks systematic error") on analyzed position component differences was made. Because analyzed period covered the years 2016-2017 and the switch from IBb08/igs08.atx to IGS14/igs14.atx took place on January 29, 2017, the influence of described systematic error on analyzed difference should revel in coordinate or analyzed coordinate difference time series (as in first period ephemeris and clocks were expressed in IBb08 model and igs08.atx/igs14.atx files were used in analysis, while in second period ephemeris and clocks were expressed in IGS14 model and the same two atx files were used).

\section{COMPARISON OF THE IGSO8.ATX AND IGS14.ATX PCC MODELS}

The most important changes in the igs14.atx file in comparison to the previous version (igs08.atx) include (Rebischung et al., 2016; Rebischung and Schmid, 2016):

- satellite antenna corrections consistent with IGS14,

- GPS satellites' $z$ component offsets calculated based on the results of 7 instead of 5 analysis centres,

- $\quad$ for the IIR block satellites, the $x$ and $y$ component offsets were determined "pre-flight" (Dilssner et al., 2016),

- $\quad$ adding the absolute field calibration results for 17 new antenna types, 


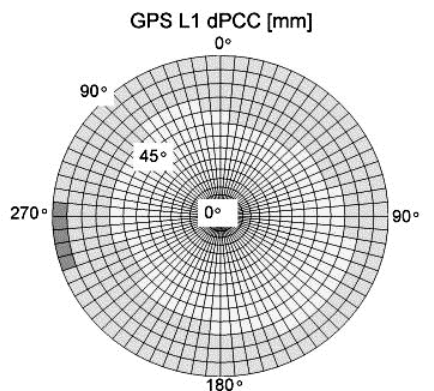

GLONASS L1 dPCC [mm]
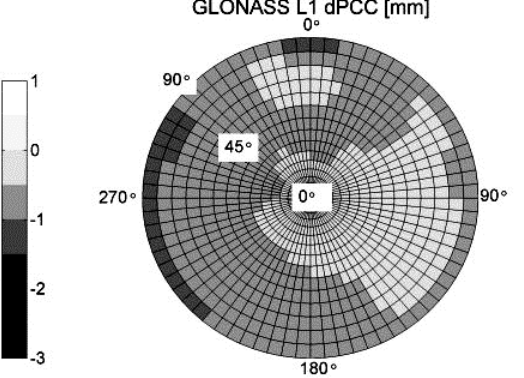

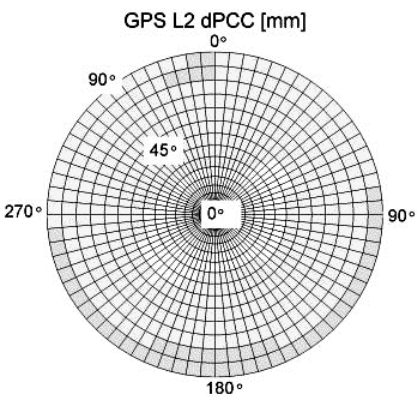

$180^{\circ}$

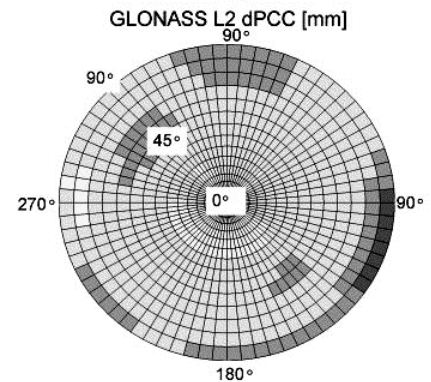

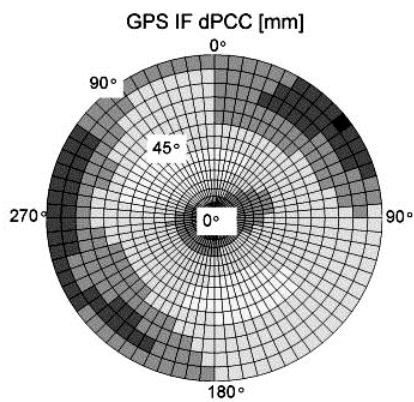

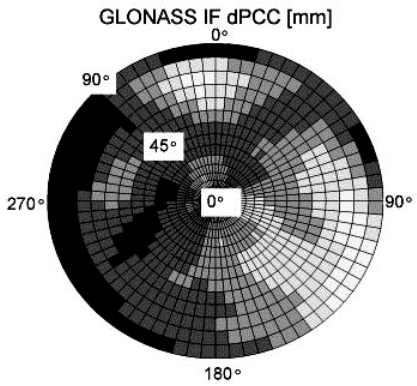

Fig. 1 PCC differences caused by actualization igs08.atx to igs14.atx obtained for LEIAR25.R3 LEIT antenna.
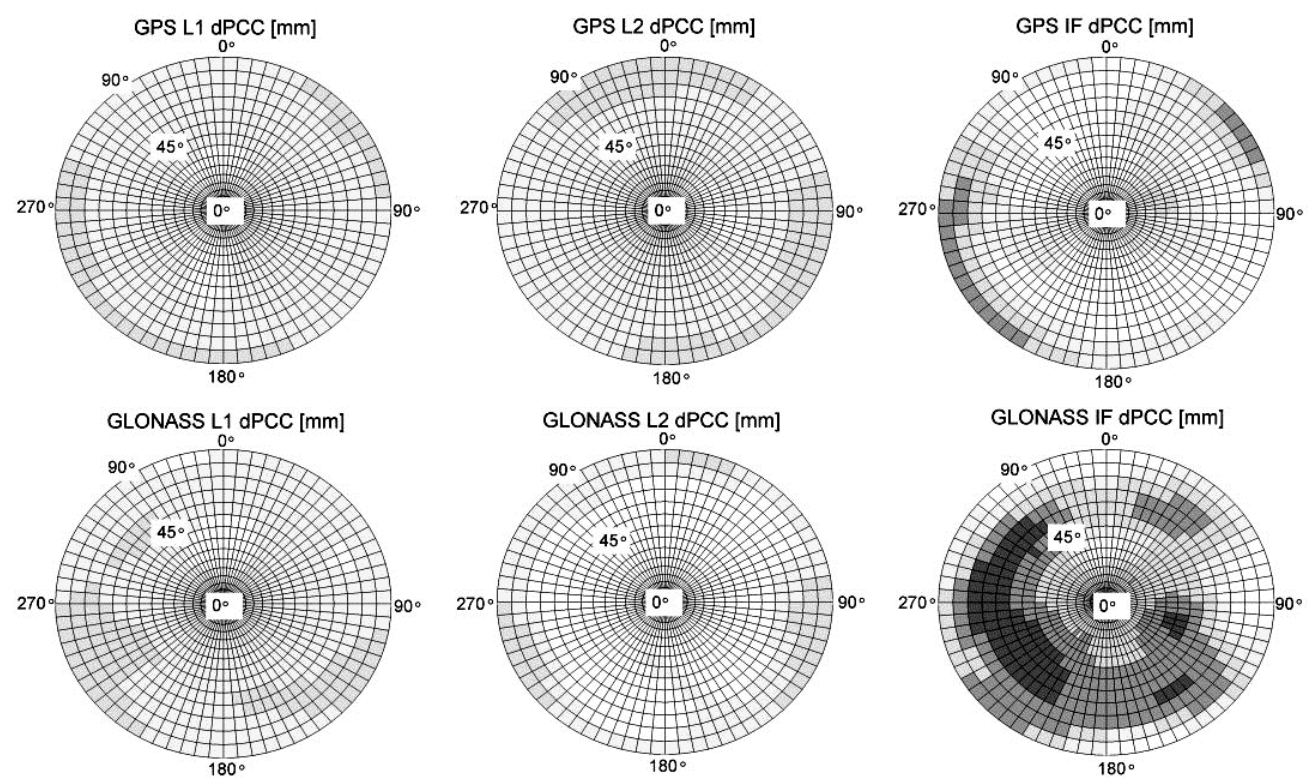

Fig. 2 PCC differences caused by actualization igs08.atx to igs14.atx obtained for LEIAR25.R3 NONE antenna.

- adding the results of "re-calculated" (converted from relative) models for 2 new types of antennas as well as updating the results of "re-calculated" (converted from relative) models for 11 types of antennas,

- updating the results of absolute field calibration for 19 types of antennas, including the LEIAR25.R3 NONE, LEIAR25.R3 LEIT and LEIAR25.R4 LEIT antenna models, adding the absolute field calibration results for GLONASS signals for 4 antenna types.
The basic elements of PCC models of receiver antennas are:

- North, East, Up offsets for L1 and L2 frequencies of GPS and GLONASS signals,

- $\mathrm{PCV}$ in the elevation function for L1 and L2 frequencies of GPS and GLONASS signals,

- $\quad$ PCV in the elevation and azimuth function for L1 and L2 frequencies of GPS and GLONASS signals. 

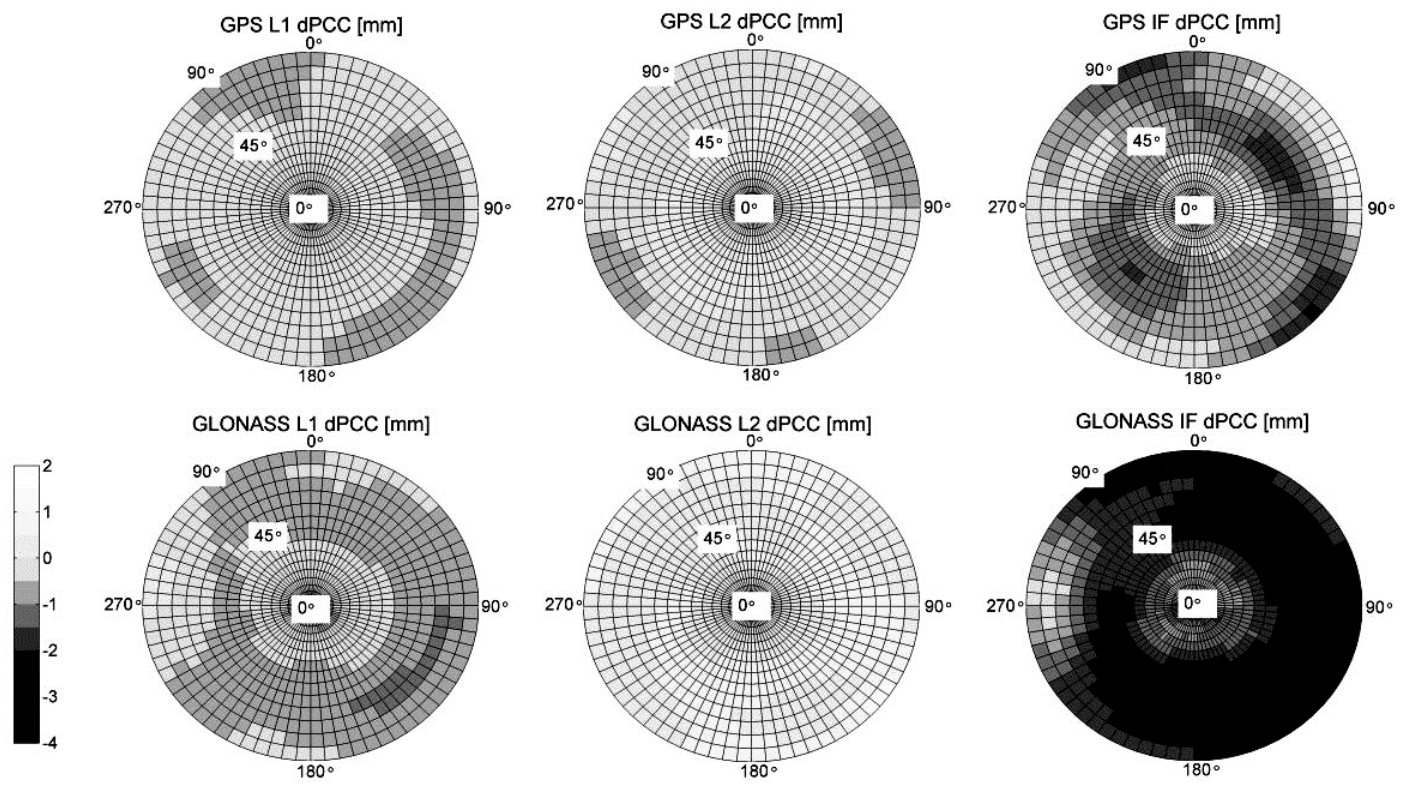

Fig. 3 PCC differences caused by actualization igs08.atx to igs14.atx obtained for LEIAR25.R4 LEIT antenna.
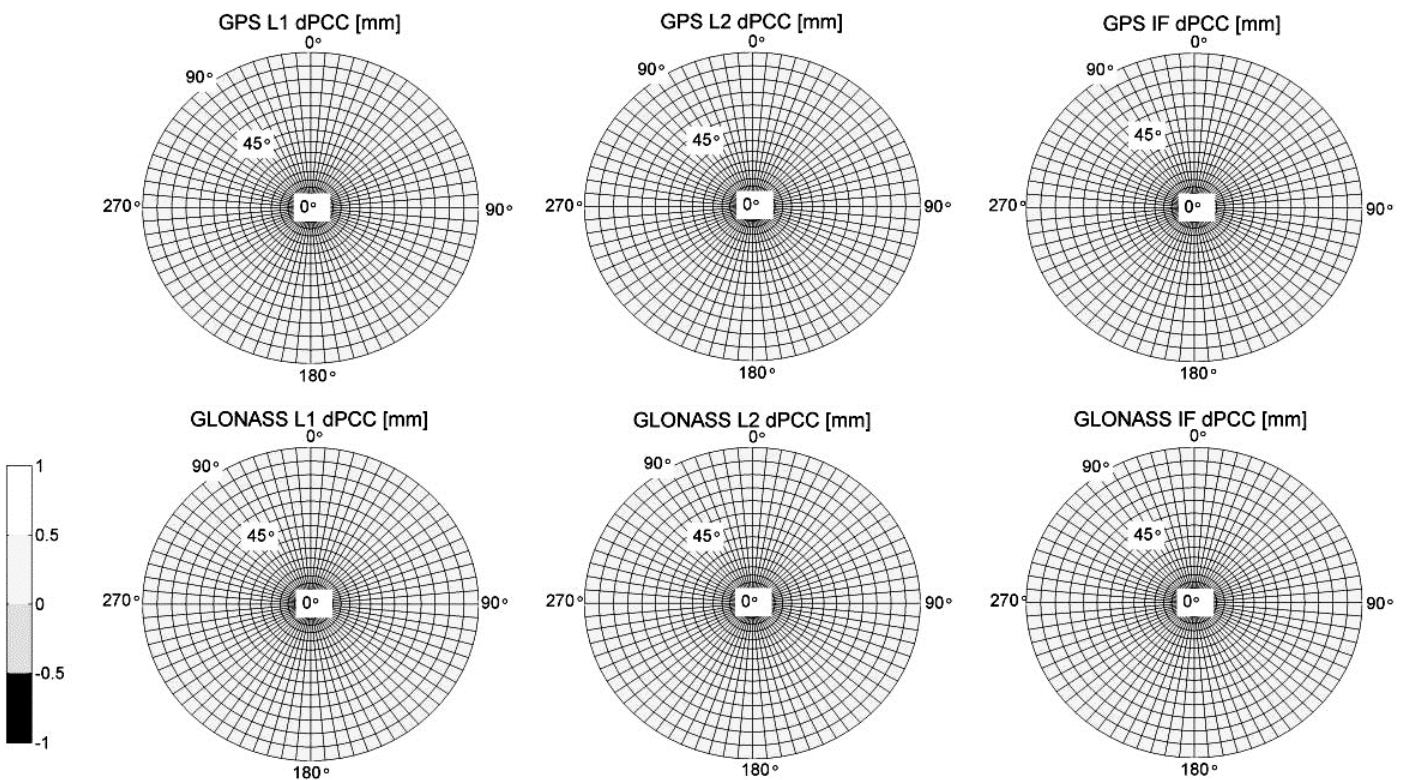

Fig. 4 PCC differences caused by actualization igs08.atx to igs14.atx obtained TRM59900.00 SCIS antenna.

The precise knowledge of both values (PCO and $\mathrm{PCV})$ is necessary to determine the PCC, i.e. the difference between the real position of the antenna phase centre of the current observation and the antenna reference point (ARP).

Comparison of PCC models for antennas used in the study is based on PCO as well as elevation and azimuth dependent PCV. For all selected antenna types (also for the TRM59900.00 SCIS antenna where there were no changes in the PCC model due to the switching from igs08.atx to igs14.atx), the data from the igs08.atx file were reduced to the offset values present in the igs14.atx file and then PCC differences (dPCC) were calculated for L1, L2 frequencies as well as "iono-free" (IF) combinations for both GPS and GLONASS signals. The comparison was based on an approach proposed by Schön and Kersten (2014). The obtained PCC differences are shown in Figures 1-4.

Generally, the revealed differences (for GPS IF combination) range from 1 to $-2 \mathrm{~mm}$ for the LEIAR25.R3 LEIT antenna, from 1 to $-1 \mathrm{~mm}$ for the LEIAR25.R3 LEIT antenna and from 2 to $-2 \mathrm{~mm}$ for the LEIAR25.R4 LEIT antenna. For GLONASS signals dPCC (IF combination) are slighty larger and range from 1 to $-3 \mathrm{~mm}$ for the LEIAR25.R3 LEIT antenna, from 1 to $-2 \mathrm{~mm}$ for the LEIAR25.R3 LEIT antenna and from 2 to $-4 \mathrm{~mm}$ for the LEIAR25.R4 LEIT antenna, respectively. This may result from 
Table 2 z-PCOs differences (igs14.atx - igs08.atx) for chosen GPS and GLONASS satellites (1 June, 2016).

\begin{tabular}{|c|c|c|c|c|c|}
\hline \multicolumn{3}{|c|}{ GPS } & \multicolumn{3}{|c|}{ GLONASS } \\
\hline Block & $\mathrm{SV} / \mathrm{PRN}$ & $\mathrm{z}-\mathrm{PCO} \operatorname{diff}[\mathrm{cm}]$ & Block & $\mathrm{SV} / \mathrm{PRN}$ & $\mathrm{z}-\mathrm{PCO} \operatorname{diff}[\mathrm{cm}]$ \\
\hline IIA & $18 / 34$ & -6.76 & GLONASS-M & $15 / 716$ & -5.39 \\
\hline IIR-A & $20 / 51$ & -3.01 & GLONASS-M & $10 / 717$ & -5.33 \\
\hline IIR-A & $16 / 56$ & -3.77 & GLONASS-M & $20 / 719$ & -3.97 \\
\hline IIR-A & $14 / 41$ & -4.09 & GLONASS-M & $19 / 720$ & -5.46 \\
\hline IIR-A & $13 / 43$ & -4.12 & GLONASS-M & $13 / 721$ & -4.28 \\
\hline IIR-A & $28 / 44$ & -4.33 & GLONASS-M & $11 / 723$ & -10.03 \\
\hline IIR-A & $21 / 45$ & -4.63 & GLONASS-M & $1 / 730$ & -19.34 \\
\hline IIR-A & $11 / 46$ & -2.35 & GLONASS-M & $4 / 733$ & -4.84 \\
\hline IIR-B & $22 / 47$ & -5.52 & GLONASS-M & $5 / 734$ & -6.82 \\
\hline IIR-B & $19 / 59$ & -4.14 & GLONASS-M & $22 / 731$ & -6.40 \\
\hline IIR-B & $23 / 60$ & -4.21 & GLONASS-M & $23 / 732$ & -5.63 \\
\hline IIR-B & $2 / 61$ & -4.98 & GLONASS-M & $24 / 735$ & -2.18 \\
\hline IIR-M & $31 / 51$ & -5.89 & GLONASS-M & $9 / 736$ & -4.07 \\
\hline IIR-M & $17 / 53$ & -5.62 & GLONASS-M & $6 / 701$ & -7.88 \\
\hline IIR-M & $12 / 58$ & -7.30 & GLONASS-M & $4 / 742$ & -4.75 \\
\hline IIR-M & $15 / 55$ & -5.83 & GLONASS-M & $17 / 743$ & -12.62 \\
\hline IIR-M & $29 / 57$ & -6.53 & GLONASS-M & $3 / 744$ & -4.59 \\
\hline IIR-M & $7 / 48$ & -3.05 & GLONASS-M & $7 / 745$ & -3.71 \\
\hline IIR-M & $5 / 50$ & -4.46 & GLONASS-M & $2 / 747$ & -3.63 \\
\hline IIF & $25 / 62$ & -7.99 & & & \\
\hline IIF & $1 / 63$ & -5.95 & & & \\
\hline IIF & $30 / 64$ & -7.79 & & & \\
\hline IIF & $24 / 65$ & -19.29 & & & \\
\hline IIF & $27 / 66$ & -7.77 & & & \\
\hline IIF & $6 / 67$ & -13.30 & & & \\
\hline IIF & $9 / 68$ & -7.74 & & & \\
\hline IIF & $3 / 69$ & -4.94 & & & \\
\hline
\end{tabular}

differences in GLONASS signal calibration in comparison to GPS signals as a result of the different frequencies of GLONASSS satellites. Since GLONASS PCC were created from a mixture of observed frequencies, the calibration results are satellite constellation dependent and are not as accurate as the GPS results (Wübbena et al., 2006). In case of the TRM59900.00 SCIS antenna, all the differences equal zero, as expected.

For the three antenna models where differences were observed, as a result of switching from igs08.atx to igs14.atx, it can be also noticed:

- analysing the obtained results for chosen frequencies, it can be seen that the largest differences were obtained for the IF combination, for both GPS and GLONASS signals.

- it can be also noted that the largest differences occur for low elevation angles - these differences clearly decrease with the increase of this angle. It should be noted that the maximum differences will be neutralized in the results of the presented studies through the application of a $10^{\circ}$ elevation mask. The one exception to the observed rule is the LEIAR25.R3 NONE antenna, where for the IF combination of GLONASS signals the largest differences were obtained for elevations in the range from $15^{\circ}$ to $45^{\circ}$, in the western regions of the PCC model.

- generally, for the majority of the analysed cases, received differences are visibly elevation angle dependent (this applies to almost all GPS and GLONASS dPCC received for both L1 and L2 frequencies). For the IF solutions, it can also be seen that the differences depend on both the elevation and the azimuth angles.

In addition to the changes in the receiver antennae models, some changes were also introduced in the $z$-PCOs of both GPS and GLONASS satellites. These changes have been forced by a number of modifications in various models (e.g. Earth Radiation pressure, antenna thrust). On average, the $z$-PCOs of satellite antennas decreased by approximately $6 \mathrm{~cm}$ during the switching from igs08.atx to igs14.atx (Rebischung and Schmid, 2016). The detailed $z$-PCO differences for GPS and GLONASS satellites observed on June 1, 2016 are presented in Table 2.

As can be seen in Table 2, the scattering of $z$ PCO differences is significant. For GPS satellites, it ranges from -2.35 to $-19.29 \mathrm{~cm}$, while for GLONAS satellites the $z$-PCO differences range from -2.18 to $19.34 \mathrm{~cm}$. 

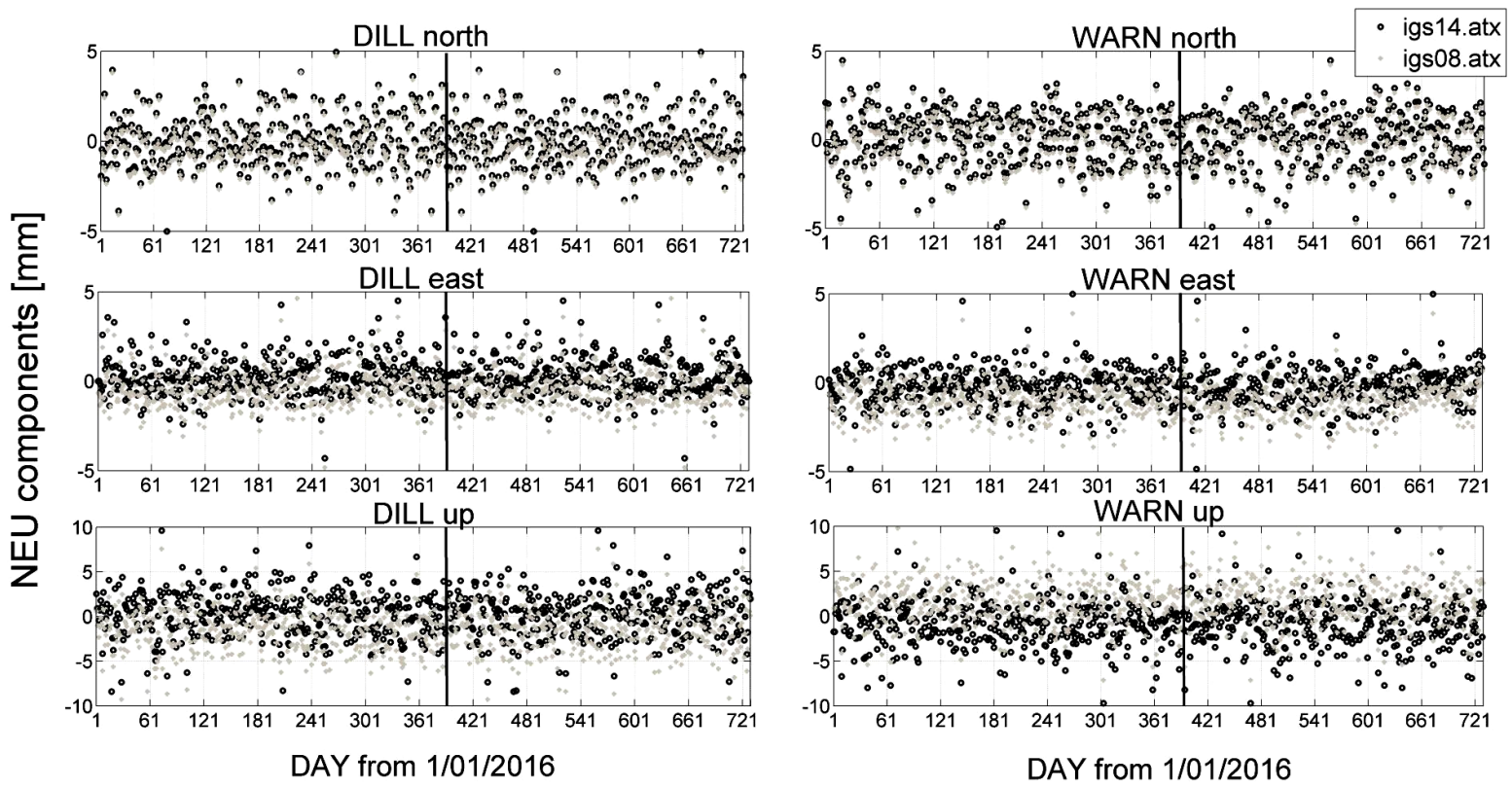

Fig. 5 Station DILL and WARN North, East, Up position components in daily GPS-only solution (vertical line indicates to moment of switching from IBb08/igs08.atx to IGS14/igs14.atx).

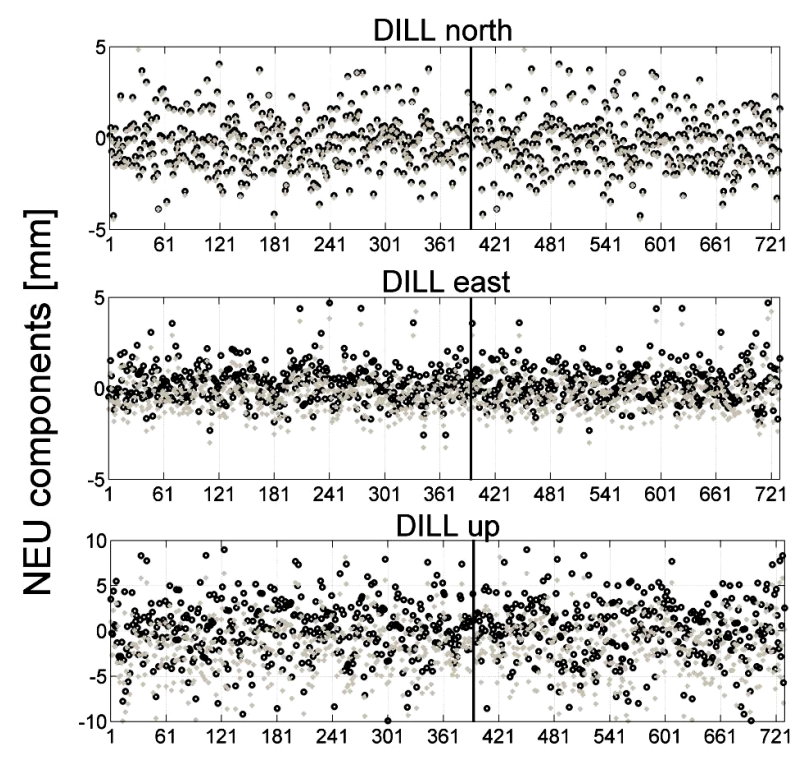

DAY from $1 / 01 / 2016$

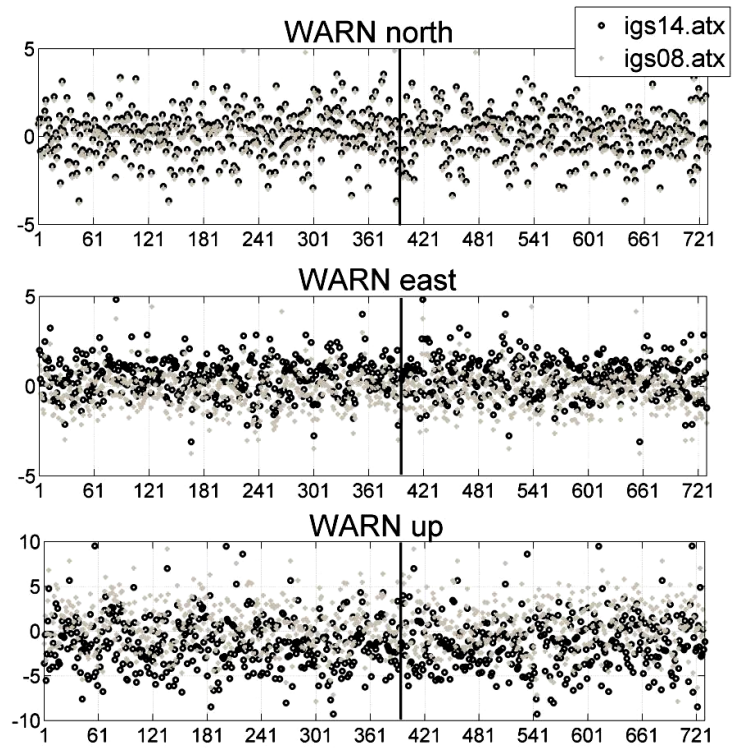

DAY from $1 / 01 / 2016$

Fig. 6 Station DILL and WARN North, East, Up position components in daily GLONASS-only solution (vertical line indicates to moment of switching from IBb08/igs08.atx to IGS14/igs14.atx).

\section{THE POSITION COMPONENT DIFFERENCES IN DAILY OBSERVATION PROCESSING VARIANTS}

For purposes of the analysis, position component time series were created at daily intervals, covering 731 days (2016 and 2017). The two-years time series of solutions allows both the analysis of stability as well as the significance (from the practical and statistical point of view) of the obtained differences. Additionally, as the switch from IBb08/igs08.atx to IGS14/igs14.atx took place on January 29, 2017, an attempt to estimate the influence of mentioned in Introduction "ephemeris and clocks systematic error", on analyzed position component differences can be made. The purpose of the analysis is to determine the differences of the station position components, as a result of switching PCC models from the igs08.atx to igs14.atx. Because in the PPP method, the reference system is based on the satellite constellation and the best selection for a reference frame is that which follows the reference frame of the orbits (IGb08 or IGS14), all observation were processing using "free network" method: until 28 January, 2017 in the IGb08 system, from 29 January, 2017 in IGS14 system.

By assumption, the analysis of the time series should be referred to topocentric coordinates 

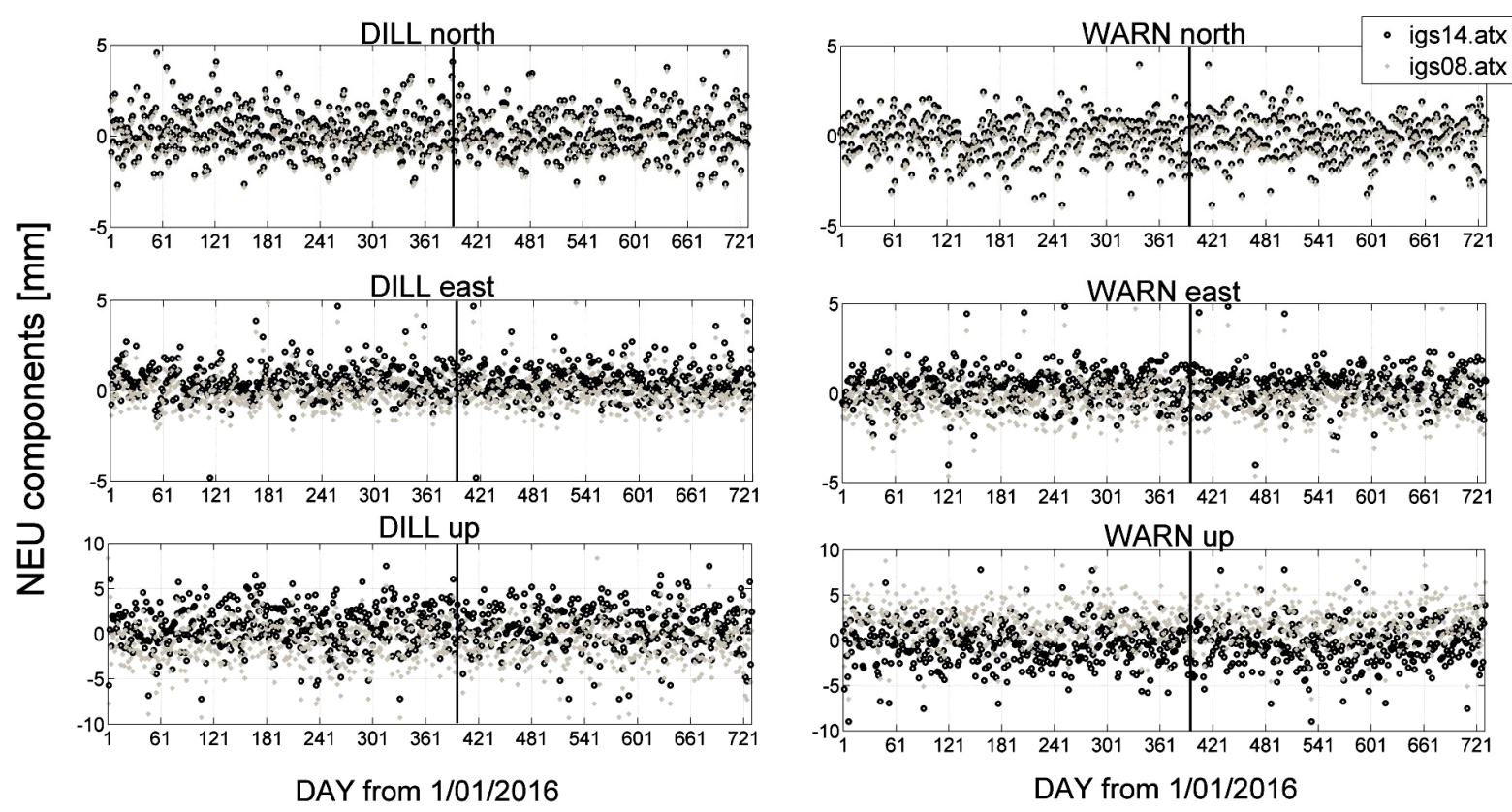

Fig. 7 Station DILL and WARN North, East, Up position components in daily GNSS solution (vertical line indicates to moment of switching from IBb08/igs08.atx to IGS14/igs14.atx).

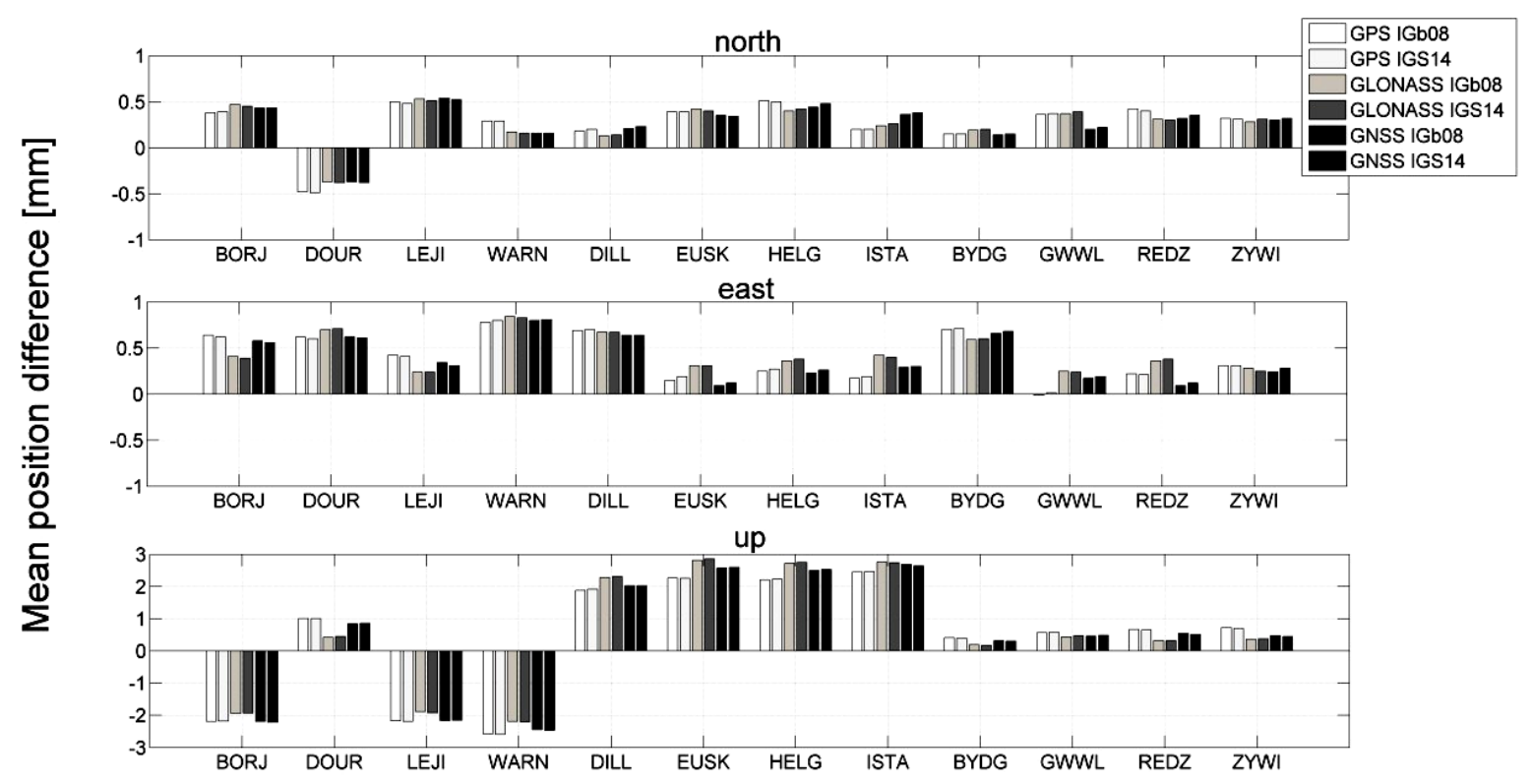

Fig. 8 The mean differences in the NEU position components obtained from the comparison of solutions using the igs08.atx and igs14.atx antenna calibration models.

(horizontal components $\mathrm{N}, \mathrm{E}$ and vertical component $\mathrm{U})$. The position time series were converted to the topocentric system according to well-known formulas (Hofmann-Wellenhof et al., 2001).

Figures 5-7 present the time series of the daily co-ordinate changes (for station DILL and WARN), which allows to look on the accuracy of PPP positioning during the research period as well as allows estimation the influence of the switch from IGb08 to IGS14 on analyzed differences. The mean differences in the NEU position components obtained from the comparison of solutions using the igs08.atx and igs14.atx antenna calibration models are presented in Figure 8. Due to some visible differences in the obtained GPS and GLONASS APCC, the observations were processed using the PPP technique in three variants: using GPS-only (GPS) observations, GLONASS-only observations (GLONASS) and using combined GPS and GLONASS solution (GNSS).

Analysing the results presented in Figure 5, it can be seen that:

- NEU coordinates generally do not exceed $\pm 5 \mathrm{~mm}$ for horizontal components and $\pm 10 \mathrm{~mm}$ for the vertical component, 
Table 3 Comparison of mean position component differences obtained in the IGb08 and IGS14 system (daily processing variants).

\begin{tabular}{lrrrrrrrrr}
\hline Station & \multicolumn{9}{c}{ Comparison of mean position component differences (IGS14-IGb08) [mm] } \\
\cline { 2 - 10 } & \multicolumn{3}{c}{ GPS-only } & \multicolumn{3}{c}{ GLONASS-only } & \multicolumn{4}{c}{ GNSS } \\
\cline { 2 - 10 } & North & East & \multicolumn{1}{c}{ Up } & North & East & Up & North & East & Up \\
\hline BORJ & 0.01 & -0.02 & -0.01 & -0.02 & -0.02 & 0.01 & 0.00 & -0.02 & -0.03 \\
DOUR & -0.01 & -0.02 & 0.00 & -0.01 & 0.01 & 0.03 & -0.01 & -0.01 & 0.02 \\
LEJI & -0.02 & -0.01 & -0.02 & -0.02 & 0.00 & -0.03 & -0.02 & -0.03 & 0.01 \\
WARN & 0.00 & 0.02 & -0.02 & -0.01 & -0.01 & -0.02 & 0.00 & 0.01 & -0.01 \\
DILL & 0.02 & 0.01 & 0.03 & 0.01 & 0.00 & 0.03 & 0.02 & 0.00 & 0.00 \\
EUSK & 0.00 & 0.04 & -0.01 & -0.02 & 0.00 & 0.05 & -0.01 & 0.03 & 0.02 \\
HELG & -0.01 & 0.02 & 0.02 & 0.02 & 0.02 & 0.02 & 0.04 & 0.03 & 0.03 \\
ISTA & 0.00 & 0.02 & 0.01 & 0.02 & -0.02 & -0.02 & 0.02 & 0.01 & -0.04 \\
BYDG & 0.00 & 0.01 & -0.02 & 0.01 & 0.01 & -0.02 & 0.01 & 0.02 & -0.02 \\
GWWL & 0.01 & 0.02 & 0.01 & 0.01 & -0.01 & 0.04 & 0.02 & 0.02 & 0.03 \\
REDZ & -0.02 & -0.01 & -0.02 & -0.02 & 0.02 & 0.00 & 0.03 & 0.03 & -0.04 \\
ZYWI & -0.01 & 0.00 & 0.00 & -0.02 & -0.03 & 0.01 & 0.02 & 0.04 & -0.03 \\
\hline
\end{tabular}

- there are visible differences (especially for Up component) between solutions using igs08.atx and igs14.atx files,

- $\quad$ the switch from IBb08 to IGS14 does not reveal visibly in NEU position components (if atx file remains unchanged).

Additionaly some increase of scaterring in obtained position time series can be observed (especially for DILL North and Up components) in comparison to GPS-only solutions.

Analysing the results presented in Figure 7 (GNSS solutions), can also be observed the previously noted phenomenons. It should be noted that GNSS solutions are characterized by the lowest scattering of obtained position time series.

Generally, for all analyzed stations, the standard deviation (SD) of GPS-only results do not exceed $\pm 1.9 \mathrm{~mm}, \pm 1.1 \mathrm{~mm}$ and $\pm 2.7 \mathrm{~mm}$ (for North, East and Up components respectively) for the both periods (before and after switch from IBb08 to IGS14). In the case of GLONASS-only solution SD do not exceed $\pm 1.9 \mathrm{~mm}, \pm 1.1 \mathrm{~mm}$ and $\pm 3.4 \mathrm{~mm}$ (for results until 28 January, 2017) and $\pm 2.0 \mathrm{~mm}, \pm 1.2 \mathrm{~mm}$ and $\pm 3.4 \mathrm{~mm}$ (for results from 28 January, 2017). Finally, for GNSS solutions SD do not exceed $\pm 1.6 \mathrm{~mm}, \pm 1.0 \mathrm{~mm}$ and $\pm 2.5 \mathrm{~mm}$ (for North, East and Up components respectively) for the both analyzed periods.

Figure 8 presents the mean differences in the NEU position components obtained from the comparison of solutions using the igs08.atx and igs14.atx antenna calibration models. These differences were estimated in both analyzed periods (until 28 January, 2017 in the IGb08 system and from 29 January, 2017 in IGS14 system).

Analysing the results presented in Figure 8, it can be seen that:

- coordinate differences obtained for the station with the LEIAR25.R3 LEIT antenna (BORJ, LEJI, WARN) are very similar for all stations and all processing variants and are approx. $-2 \mathrm{~mm}$ for the vertical component and not exceed $\pm 1 \mathrm{~mm}$ for horizontal components,
- the coordinate differences obtained for stations with the LEIAR25.R3 NONE antenna (DOUR) generally do not exceed $\pm 1 \mathrm{~mm}$,

- the obtained horizontal components differences for the station with the LEIAR25.R4 antenna, are very similar and do not exceed $\pm 0.5 \mathrm{~mm}$,

- for the vertical component the obtained differences are processing variant dependent (GPS-only, GLONASS-only, GNSS) and range from about $2 \mathrm{~mm}$ (GPS-only solution) to about $3 \mathrm{~mm}$ (GLONASS-only solution),

- in the case of stations with the TRM59900.00 SCIS antenna, differences can be also observed in all three position components as a result of switching from igs08.atx to igs14.atx. Although these differences are small, and in all cases do not exceed $\pm 1 \mathrm{~mm}$, their occurrence may be surprising, considering the zero differences in the receiver antenna PCC models. One of the reasons for the occurrence of these differences can be the differences present in satellite antenna models. Studies have shown that there is some impact of changing satellite offsets on positioning. Chatazinikos et al. (2009) demonstrated that switching from standard IGS antenna offsets to absolute PCC (for the antennas of satellites in a local network) caused changes in the Up component of about $\pm 0.5 \mathrm{~mm}$.

- results obtained for three variants of solution (GPS-only, GLONASS-only, GNSS) differ slightly and this mainly involves the GLONASSonly solution, whose results vary within 0.2$0.3 \mathrm{~mm}$ in comparison to the other two solution results. This can be caused by differences in GPS and GLONASS dPCC.

- $\quad$ mean differences obtained until 28 January, 2017 in the IGb08 system and from 29 January, 2017 in IGS14 system are very similar (Table 3) which may indicate that using ephemeris and clock expressed in IGb08 together with igs14.atx file or 


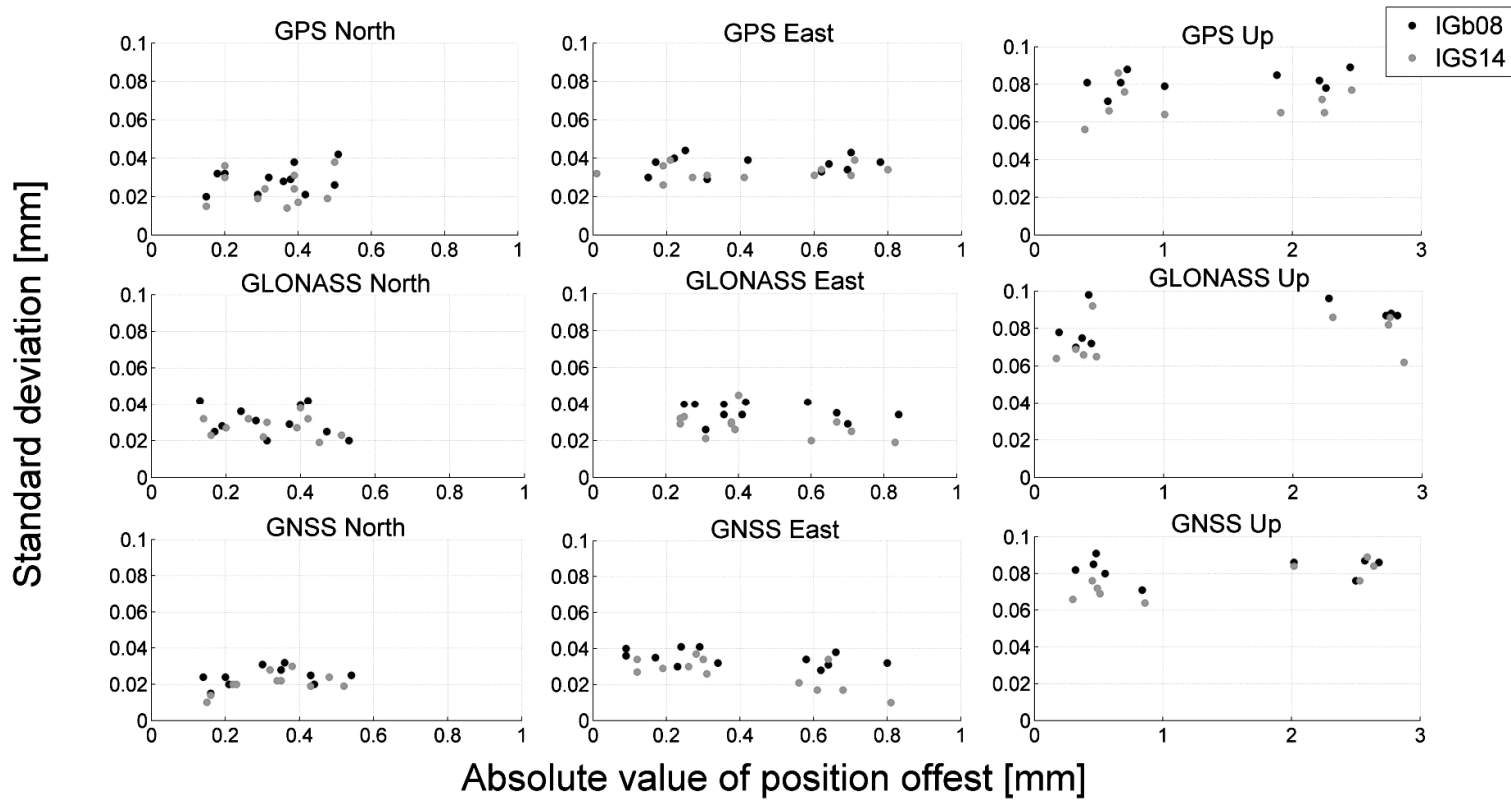

Fig. 9 Standard deviations of estimated position differences in comparison to absolute values of the obtained differences for NEU components in daily processing.

ephemeris and clock expressed in IGS14 together with igs08.atx file affect results in the same way.

Generally, it can be seen that for horizontal components, the differences in all cases do not exceed $\pm 1 \mathrm{~mm}$, and for the vertical component $\pm 3 \mathrm{~mm}$. Furthemore, in the case of a GPS-only solution, only $29 \%$ of horizontal components differences exceed $\pm 0.5 \mathrm{~mm}$. For GLONASS-only and GNSS solutions, $20 \%$ and $25 \%$ were received, respectively. For the vertical component, considering only eight stations where changes in receiver antenna PCC were observed, $75 \%$ of differences exceed $\pm 2 \mathrm{~mm}$ in the GPS-only solution. For GLONASS-only and GNSS solutions, $62 \%$ and $88 \%$ were obtained, respectively.

In the obtained results, a correlation can also be observed (especially for the vertical position component) between the value of the analysed difference and the antenna type (about $-2 \mathrm{~mm}$ for stations with LEIAR25.R3 LEIT antenna and about $2 \mathrm{~mm}$ for stations with LEIAR25.R4 LEIT antenna).

Table 3 presents comparison of mean position component differences obtained in the IGb08 system (observation period from 1.01.2016 until 28.01.2017) and in IGS14 system (period from 29.01.2017 until 31.12.2017): "IGS14 mean position difference" minus "IGb08 mean position difference". Analyzed differences, calculated in both periods, are consistent at the level of $\pm 0.05 \mathrm{~mm}$.

Standard deviations of the time series of position component differences obtained from daily observation windows were used to characterize the precision of their determination (Fig. 9).

If it is assumed (like Rebischung et al., 2011 and Baire et al., 2013) that obtained position component differences are statistically significant, if their absolute values exceed threefold the standard deviation value, in the case of the GPS-only processing variant, $100 \%$ of the determined differences for the North component, $83 \%$ of the determined differences for the East component and $100 \%$ of the determined differences for the Up component can be considered significant. In the GLONASS-only solution, these values are: $100 \%$, $100 \%, 83 \%$, respectively. For the GNSS solution, $100 \%, 75 \%$ and $100 \%$ statistically significant differences in the position components were obtained.

\section{THE POSITION COMPONENT DIFFERENCES IN SUB-DAILY OBSERVATION PROCESSING VARIANTS}

PPP results using 24-hour observations are characterized by millimetre accuracy, both in the integer ambiguity of phase measurements determination as well as in the float solution variants. The results obtained in different studies prove (Alkan and Öcalan, 2013; Mohammed et al., 2016) that in the case of short, sub-hours sessions this accuracy significantly falls. This part of the paper contains analysis regarding the impact of updating PCC models on a sub-daily derived position component time series.

The time series of NEU component obtained from 30 minute observation windows processing for example stations (DILL and WARN) are shown in Figures 10-12.

Analysing the results presented in Figure 10, it can be seen that:

- NEU coordinates generally do not exceed $\pm 2 \mathrm{~cm}$ for horizontal components and $\pm 4 \mathrm{~cm}$ for the vertical component, 


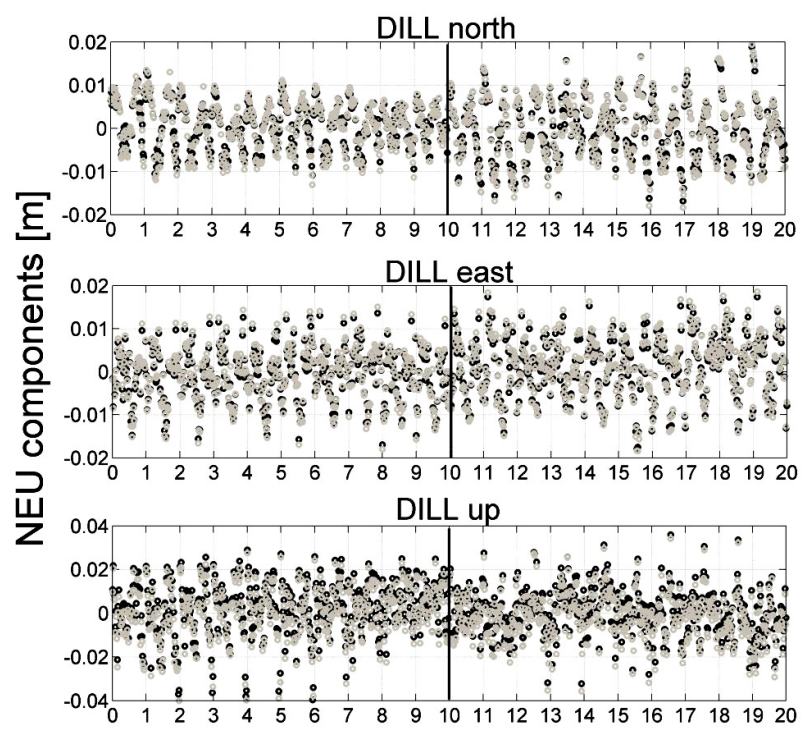

Day from 19/01/2017
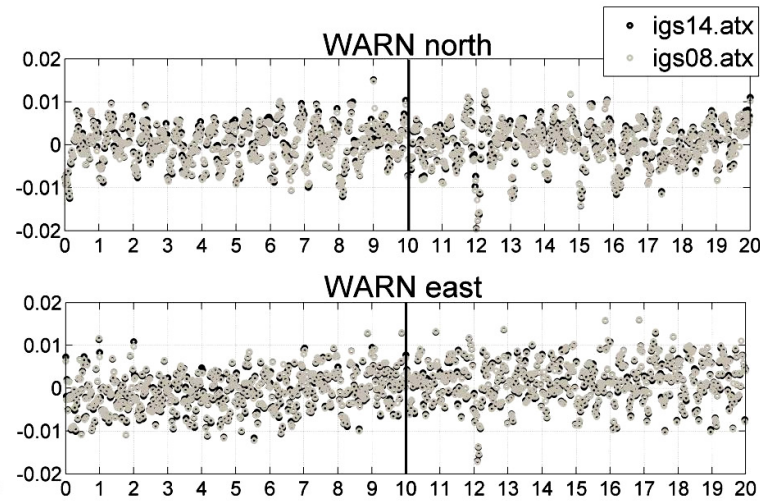
WARN up

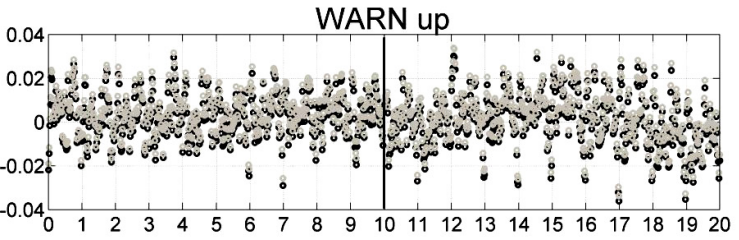

Day from 19/01/2017

Fig. 10 Station DILL and WARN North, East, Up position components in sub-daily GPS-only solution (vertical line indicates to moment of switching from IBb08/igs08.atx to IGS14/igs14.atx).

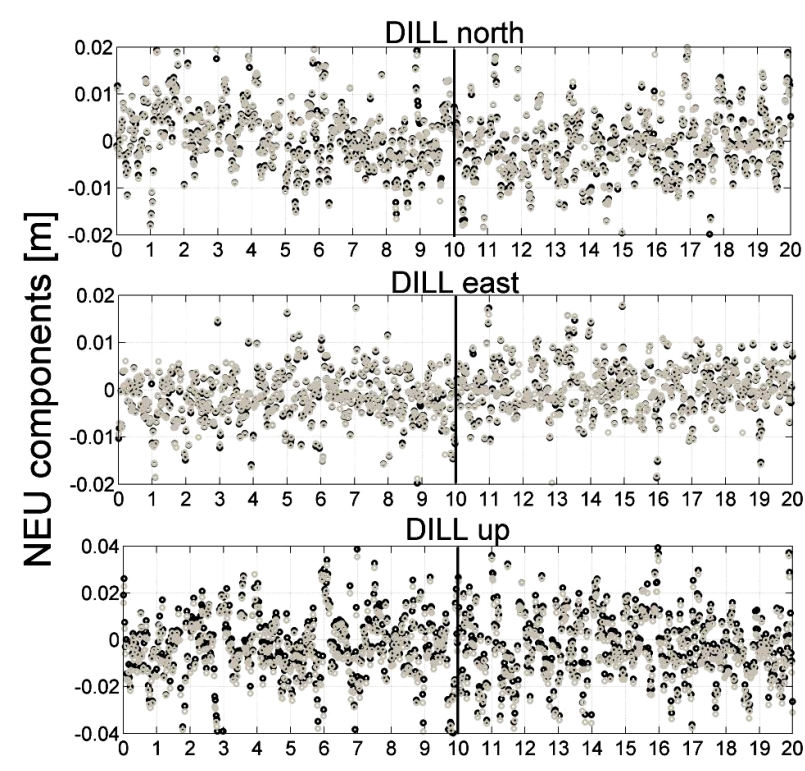

Day from 19/01/2017

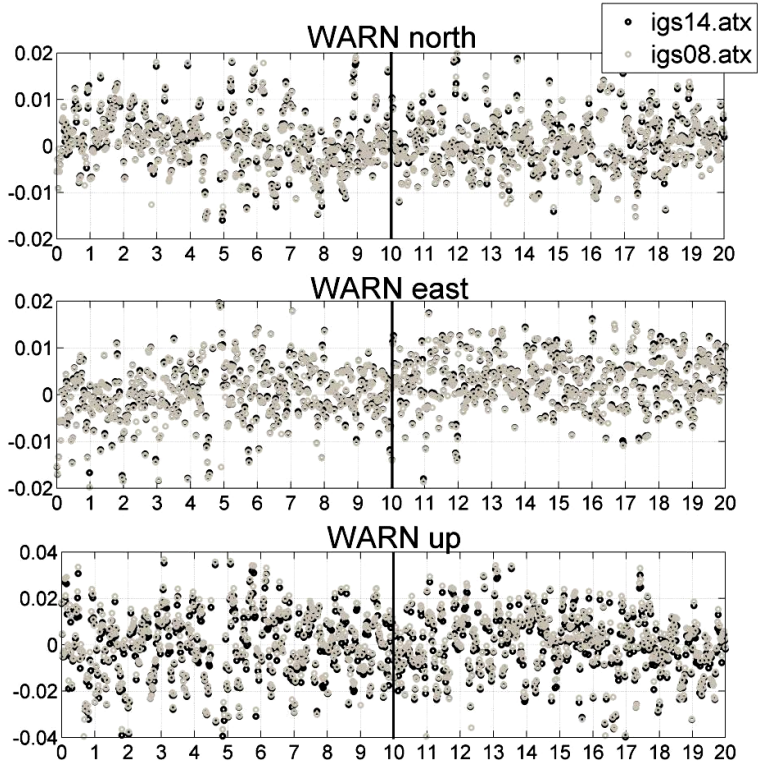

Day from 19/01/2017

Fig. 11 Station DILL and WARN North, East, Up position components in sub-daily GLONASS-only solution (vertical line indicates to moment of switching from IBb08/igs08.atx to IGS14/igs14.atx).

- there are visible systematic differences (especially for Up component) between solutions using igs08.atx and igs14.atx files,

- the switch from IBb08 to IGS14 reveal only slightly in NEU position components (change in the scattering of results visible in North DILL, Up DILL and Up WARN position components).

- the position components show rapid changes in short periods of time, what is associated with satellite constellation: the orbital period of GPS satellites or with the number of orbital planes for GLONASS satellites (Meindl, 2011; Sidorov and Teferle, 2013; Dawidowicz and Krzan, 2016; Dawidowicz, 2018).

The results obtained for the GLONASS-only solution (Fig. 11) are very similar to GPS one. As previously, they show that:

- horizontal components generally do not exceed $\pm 2 \mathrm{~cm}$ and vertical component do not exceed $\pm 4 \mathrm{~cm}$, 

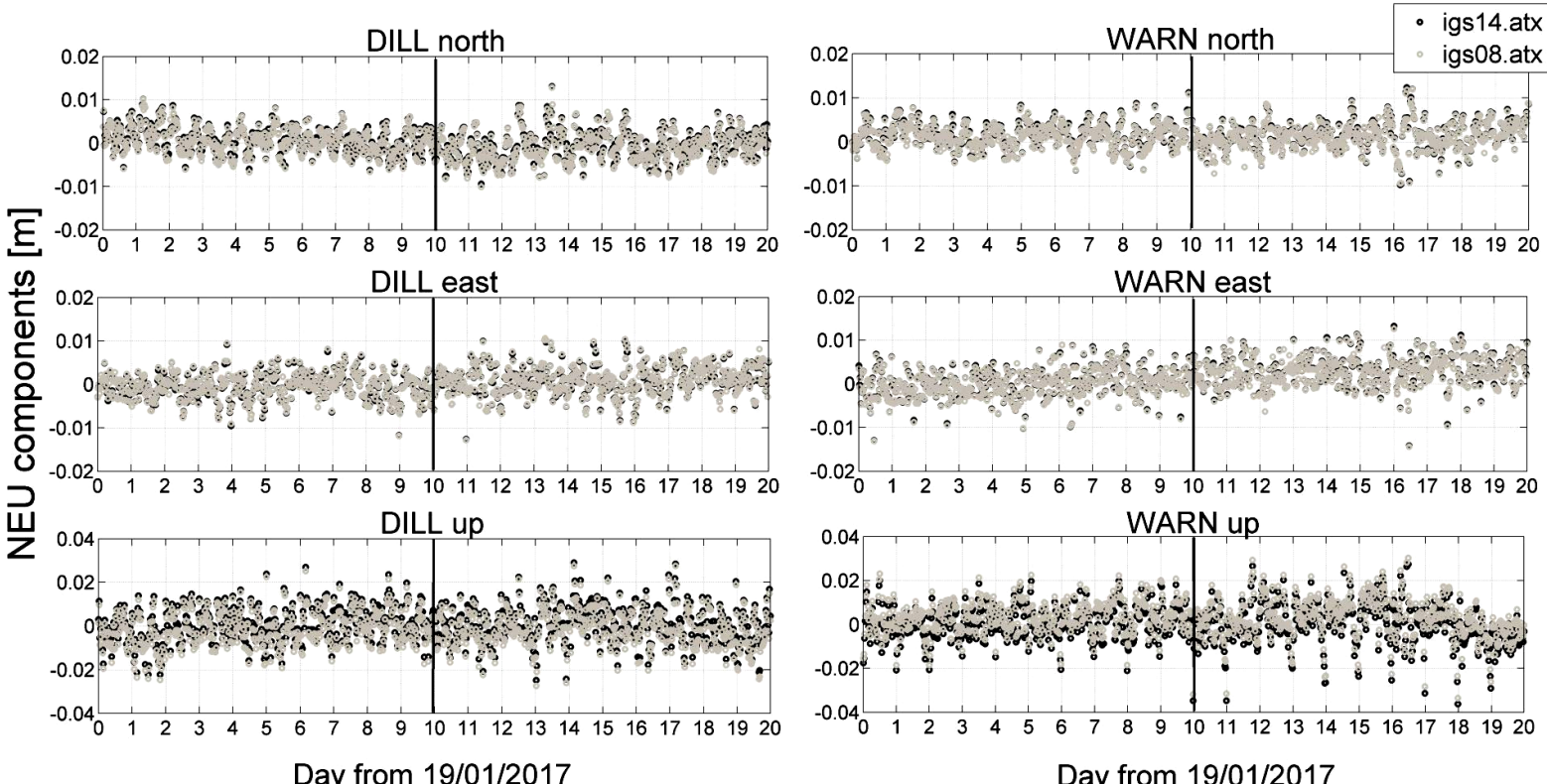

Day from 19/01/2017

Fig. 12 Station DILL and WARN North, East, Up position components in sub-daily GNSS solution (vertical line indicates to moment of switching from IBb08/igs08.atx to IGS14/igs14.atx).

- $\quad$ some visible differences between solutions using igs08.atx and igs14.atx files can be noticed,

- because some increase of scattering in obtained position time series can be observed in comparison to GPS-only solutions, the switch from IBb08 to IGS14 does not reveal visibly in position components.

- the differences, as previously, show rapid changes in short periods of time.

Analysing the results presented in Figure 12 (GNSS solutions), can be also observed the previously noted phenomenons. It should be also noted that GNSS solutions are characterized by the lowest scaterring of obtained position time series: horizontal components generally do not exceed $\pm 1 \mathrm{~cm}$ and vertical component do not exceed $\pm 2 \mathrm{~cm}$.

Generally, for all analyzed stations, the standard deviation (SD) of GPS-only results do not exceed $\pm 0.6 \mathrm{~cm}, \pm 0.6 \mathrm{~cm}$ and $\pm 1.3 \mathrm{~cm}$ (for North, East and Up components respectively for results until 28 January, 2017) and $\pm 0.8 \mathrm{~cm}, \pm 0.7 \mathrm{~cm}$ and $\pm 1.2 \mathrm{~cm}$ (for results from 28 January, 2017). In the case of GLONASS-only solution SD do not exceed $\pm 2.7 \mathrm{~cm}$, $\pm 1.7 \mathrm{~cm}$ and $\pm 4.4 \mathrm{~cm}$ (for results until 28 January, 2017) and $\pm 1.5 \mathrm{~cm}, \pm 0.9 \mathrm{~cm}$ and $\pm 2.2 \mathrm{~cm}$ (for results from 28 January, 2017). Finally, for GNSS solutions SD do not exceed $\pm 0.4 \mathrm{~cm}, \pm 0.4 \mathrm{~cm}$ and $\pm 1.0 \mathrm{~cm}$ (for North, East and Up components respectively) for the both analyzed periods.

Figure 13 presents the mean differences in the NEU position components obtained from the comparison of solutions using the igs08.atx and igs 14.atx antenna calibration models.

Analysing the results presented in Figure 13, it can be seen that:
- the characteristics of the obtained differences for the station with the LEIAR25.R3 LEIT antenna are very similar for all processing cases and reach up to $-3 \mathrm{~mm}$ for the vertical component and do not exceed $\pm 0.5 \mathrm{~mm}$ for horizontal components,

- differences obtained for stations with the LEIAR25.R3 NONE antenna generally do not exceed $\pm 0.5 \mathrm{~mm}$,

- the obtained differences, for the solutions with the LEIAR25.R4 antenna, are also very similar for all cases and their values reach up to $3 \mathrm{~mm}$ for the vertical component and do not exceed $\pm 0.5 \mathrm{~mm}$ for horizontal components,

- for all sub-daily solutions with the TRM59900.00 SCIS antenna, the differences in the position components did not reveal even after taking the sub-millimetre order of accuracy. Although the TRM59900.00 SCIS antenna model was not updated during the switching from igs08.atx to igs14.atx (zero dPCC differences), daily observation solutions revealed some differences in the position components (up to $\pm 0.8 \mathrm{~mm}$ for the Up component), as a result of the differences in satellite antenna models ( $z$-PCO differences). Probably, this influence does not reveal for very short observation windows.

- results obtained for three variants of solutions (GPS-only, GLONASS-only, GNSS) differ slightly (within $0.2-0.5 \mathrm{~mm}$ ). This is caused by differences visible in GPS and GLONASS dPCC,

- $\quad$ as in the case of daily solutions, mean differences obtained in the IGb08 and in IGS14 systems are very similar (Table 4). 


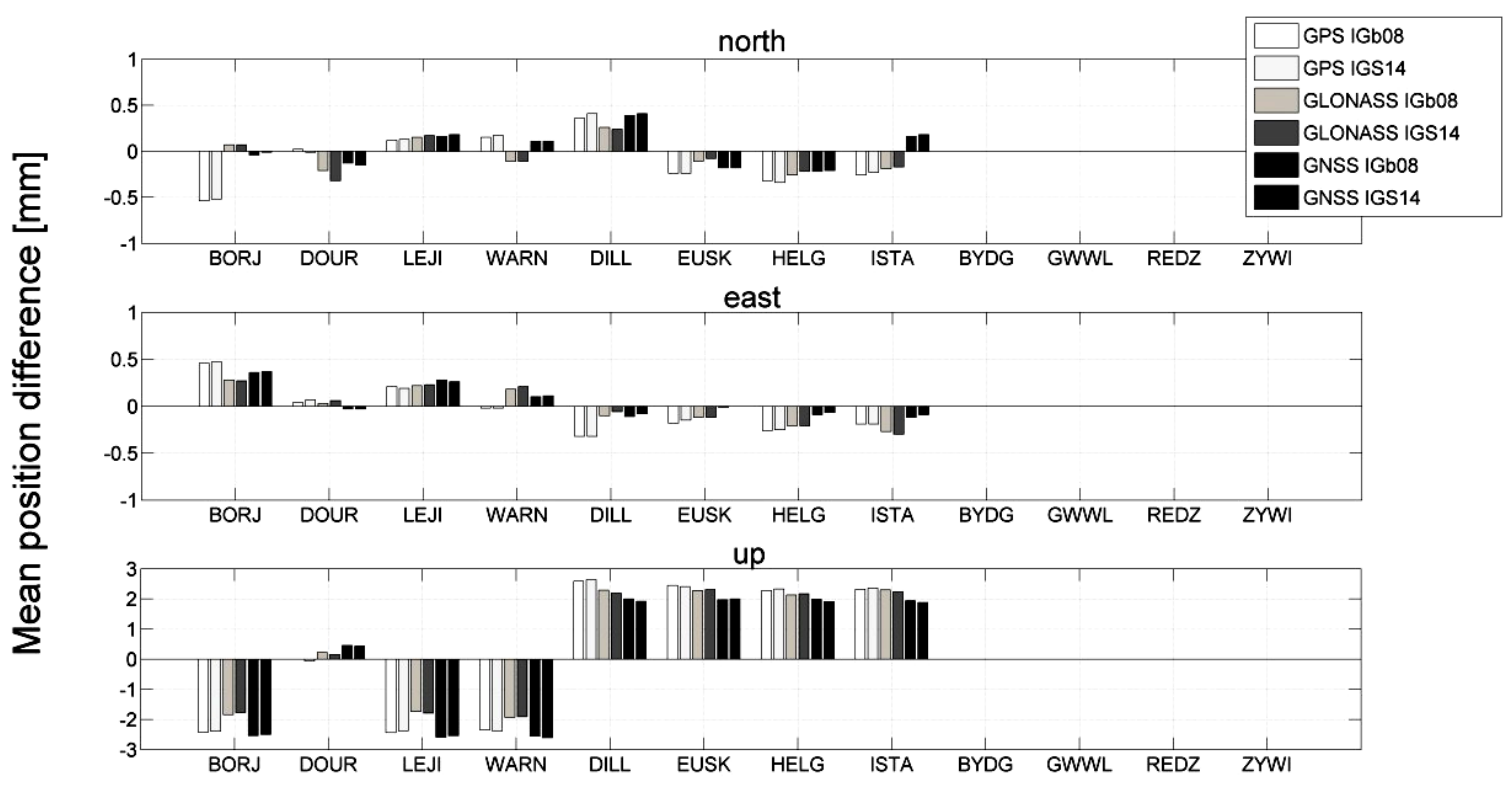

Fig. 13 The mean differences in the NEU position components obtained from the comparison of solutions using the igs08.atx and igs14.atx antenna calibration models.

Table 4 Comparison of mean position component differences obtained in the IGb08 and IGS14 system (subdaily processing variants).

\begin{tabular}{|c|c|c|c|c|c|c|c|c|c|}
\hline \multirow[t]{3}{*}{ Station } & \multicolumn{9}{|c|}{ Comparison of mean position component differences (IGS14-IGb08) [mm] } \\
\hline & \multicolumn{3}{|c|}{ GPS-only } & \multicolumn{3}{|c|}{ GLONASS-only } & \multicolumn{3}{|c|}{ GNSS } \\
\hline & North & East & Up & North & East & Up & North & East & Up \\
\hline BORJ & 0.02 & 0.01 & 0.04 & 0.00 & -0.01 & 0.07 & 0.03 & 0.01 & 0.04 \\
\hline DOUR & -0.03 & 0.03 & -0.04 & -0.07 & 0.03 & -0.03 & -0.02 & 0.00 & -0.02 \\
\hline LEJI & 0.01 & -0.02 & 0.06 & 0.02 & 0.01 & -0.05 & 0.02 & -0.02 & 0.05 \\
\hline WARN & 0.02 & 0.00 & -0.03 & 0.00 & 0.03 & 0.02 & 0.00 & 0.01 & -0.05 \\
\hline DILL & 0.05 & 0.00 & 0.05 & -0.02 & 0.04 & -0.10 & -0.02 & 0.03 & -0.08 \\
\hline EUSK & 0.00 & 0.03 & -0.04 & 0.03 & 0.00 & 0.03 & 0.00 & -0.01 & 0.03 \\
\hline HELG & -0.02 & 0.01 & 0.05 & 0.04 & 0.00 & 0.04 & 0.01 & 0.02 & -0.07 \\
\hline ISTA & 0.03 & 0.00 & 0.04 & 0.02 & -0.03 & -0.06 & 0.02 & 0.03 & -0.06 \\
\hline BYDG & 0.00 & 0.00 & 0.00 & 0.00 & 0.00 & 0.00 & 0.00 & 0.00 & 0.00 \\
\hline GWWL & 0.00 & 0.00 & 0.00 & 0.00 & 0.00 & 0.00 & 0.00 & 0.00 & 0.00 \\
\hline REDZ & 0.00 & 0.00 & 0.00 & 0.00 & 0.00 & 0.00 & 0.00 & 0.00 & 0.00 \\
\hline ZYWI & 0.00 & 0.00 & 0.00 & 0.00 & 0.00 & 0.00 & 0.00 & 0.00 & 0.00 \\
\hline
\end{tabular}

Table 4 presents comparison of mean position component differences obtained in the IGb08 system and in IGS14 system ("IGS14 mean position difference" minus "IGb08 mean position difference"). Analyzed differences, calculated in both periods, are consistent at the level of $\pm 0.1 \mathrm{~mm}$.

As for daily observations, the calculated standard deviation of the time series of position component differences were compared with the mean values of the obtained position differences (Fig. 14). Considering only eight stations where differences in the position components were noted, for sub-daily observations the following statistically significant differences were obtained:

- $0 \%$ for the North component, $0 \%$ for the East component and $87 \%$ for the Up component (in GPS-only processing results),
- $0 \%$ development for the North component, $0 \%$ for the East component and $75 \%$ for the Up component (in GLONASS-only processing results),

- $\quad 0 \%$ for the North component, $0 \%$ for the East component and $87 \%$ for the Up component (in GNSS processing results).

For sub-daily observation solutions, the lower percentage of statistically significant differences in the position components is the result of the clear periodicity, visible in all results. This increases the value of standard deviation, while the average values of differences are comparable to those obtained from daily solutions. Nevertheless, considering the results obtained for the vertical component, the percentage of statistically significant differences does not fall below $75 \%$. 

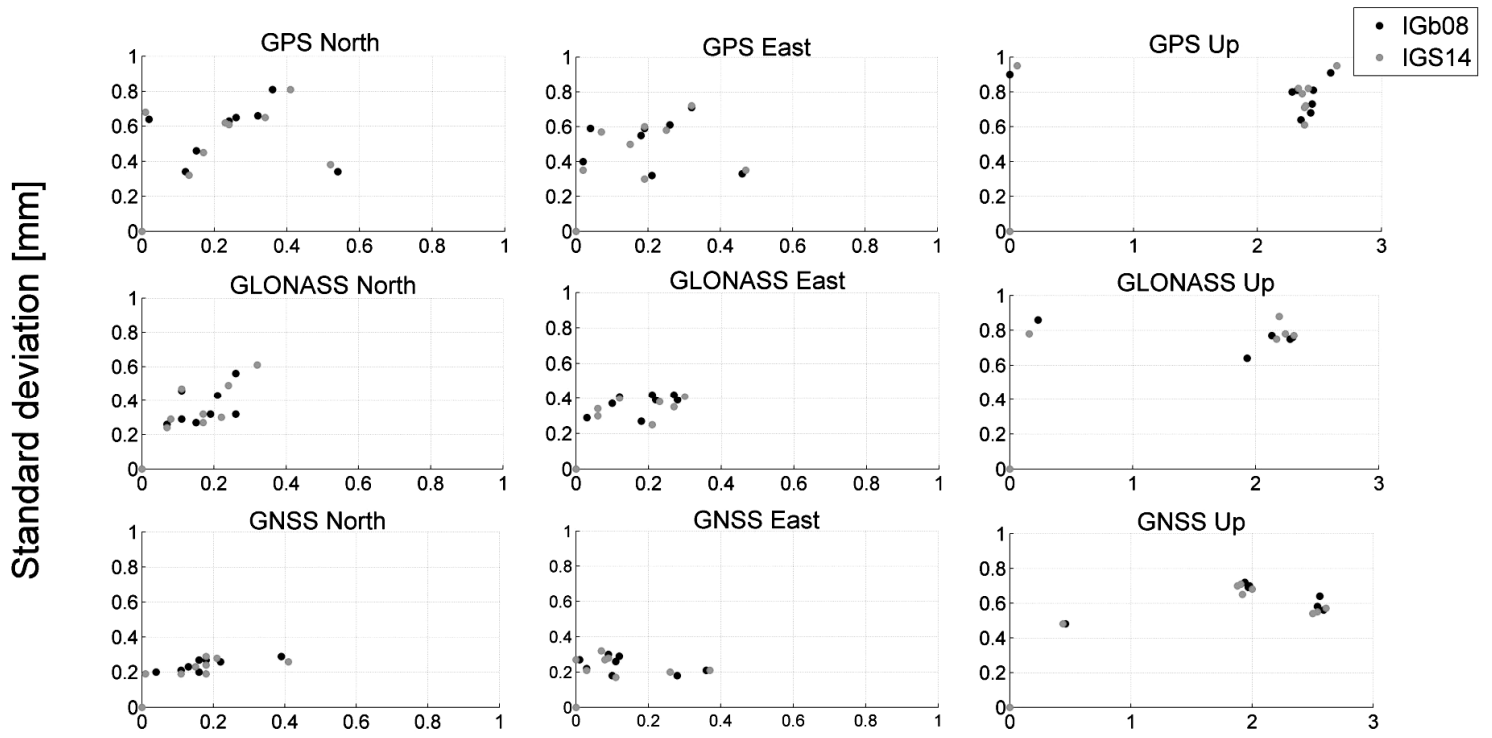

Absolute value of position offest [mm]

Fig. 14 Standard deviations of estimated position differences in comparison to absolute values of the obtained differences for NEU components in sub-daily processing.

\section{CONCLUSIONS}

In the paper, the results of the of GNSS observations processing using the PCC models included in the igs08.atx and igs14.atx files for 12 EPN and ASG-EUPOS stations were analysed, both for daily and sub-daily time series of PPP solutions. Previous changes in antenna models have resulted in changes in the estimated parameters, including station coordinates. Such changes may have particular significance in precise GNSS measurements performed for the purpose of geodynamic research, observation of continental plate motion or determination of displacements in the global coordinate system.

Generally, for antennas whose models have been updated, the revealed PCC differences range from 1 to $-3 \mathrm{~mm}$ for the LEIAR25.R3 LEIT antenna, from 1 to $2 \mathrm{~mm}$ for the LEIAR25.R3 LEIT antenna, from 2 to $4 \mathrm{~mm}$ for the LEIAR25.R4 LEIT antenna. For the TRM59900.00 SCIS antenna, the differences equal zero as expected. It should also be noted that the largest differences were obtained for the "iono-free" combination and for low elevation angles. These maximum differences were neutralized by applying a $10^{\circ}$ elevation mask.

In addition to the visible changes in the receiver antenna models, some changes were also introduced in the $z$-PCOs of both GPS and GLONASS satellites. On average, the $z$-PCOs of satellite antennas decreased by approximately $6 \mathrm{~cm}$ during the switching from igs08.atx to igs14.atx. Although for satellites observed on June 1, 2016, in the case of GPS satellites, it ranges from -2.35 to $-19.29 \mathrm{~cm}$, while for GLONAS satellites the $z$-PCO differences range from -2.18 to $-19.34 \mathrm{~cm}$.
Analysing the results obtained for the daily solutions time series, it can be noted that for horizontal components, the differences do not exceed $\pm 1 \mathrm{~mm}$, and for the vertical component $\pm 3 \mathrm{~mm}$. Furthemore, in the case of a GPS-only solution, only $29 \%$ of horizontal components differences exceed $\pm 0.5 \mathrm{~mm}$. For GLONASS-only and GNSS solutions, $20 \%$ and $25 \%$ were received, respectively. For the vertical component, considering only eight stations where changes in receiver antenna PCC were observed, $75 \%$ of differences exceed $\pm 2 \mathrm{~mm}$ in the GPS-only solution. For GLONASS-only and GNSS solutions, $62 \%$ and $88 \%$ were obtained, respectively. It is worth noting that in the case of the TRM59900.00 SCIS antenna, differences were also obtained for all three position components. These differences are small and do not exceed $\pm 1 \mathrm{~mm}$. The main reasons for the occurrence of these differences are probably the differences present in satellite antenna models.

For sub-daily observations, the differences in horizontal position components generally do not exceed $\pm 1 \mathrm{~mm}$, while for the vertical difference they reach $\pm 3 \mathrm{~mm}$. Furthermore, in the case of sub-daily solutions, considering only eight stations where dPCC were observed, only $6 \%$ of horizontal components differences exceed $\pm 0.5 \mathrm{~mm}$ for the GPS-only solution. For the GLONASS-only and GNSS solutions, $0 \%$ and $0 \%$ were obtained, respectively. For vertical component, in the GPS-only solution $88 \%$ of differences exceed $\pm 2 \mathrm{~mm}$. For the GLONASS-only and GNSS solutions $50 \%$ and $88 \%$ were received, respectively. For all sub-daily solutions with the TRM59900.00 SCIS antenna, the differences in the position components did not reveal even after taking the sub-millimetre order of accuracy. The 
satellite antenna $z$-PCO differences probably do not impact the results in the case of very short observation windows.

Analasis of differences in both periods (from 1 January, 2016 until 28 January, 2017 in the IGb08 system and from 29 January, 2017 until 31 December, 2017 in IGS14 system) revel only small discrepancy in results. In case of daily solution calculated mean differences in both periods are consistent at the level of $\pm 0.05 \mathrm{~mm}$. For sub-daily solution they are consistent at the level of $\pm 0.1 \mathrm{~mm}$. This may indicate that using ephemeris and clock expressed in IGb08 together with igs14.atx file or ephemeris and clock expressed in IGS14 together with igs08.atx file affect results in the same way.

\section{ACKNOWLEDGMENTS}

The author is grateful for GNSS data provided by the International GNSS Service, EUREF Permanent Network, and the European Space Agency (ESA) as well as for NAPEOS software made available by ESA.

\section{REFERENCES}

Alkan, R.M. and Öcalan, T.: 2013, Usability of GPS Precise Point Positioning (PPP) technique in marine applications. J. Navig., 66, 4, 579-588. DOI: $10.1017 / \mathrm{S} 0373463313000210$

Altamimi, Z., Rebischung, P., Metivier, L. and Xavier, C.: 2016, ITRF2014: A new release of the International Terrestrial Reference Frame modeling nonlinear station motions, J. Geophys. Res., Solid Earth, 121, 8, 6109-6131. DOI: 10.1002/2016JB013098

Baire, Q., Pottiaux, E., Bruyninx, C., Defraigne, P., Legrand, J. and Bergoet, N.: 2011, Comparison of Receiver Antenna Calibration Models used in the EPN. http://www.euref.eu/symposia/ 2011Chisinau/Symposium2011-Chisinau.html

Baire, Q., Bruyninx, C., Legrand, J., Pottiaux, E., Aerts, W., Defraigne, P., Bergeot, N. and Chevalier, J.M.: 2013, Influence of different GPS receiver antenna calibration models on geodetic positioning. GPS Solut., 18, 1-11. DOI: 10.1007/s10291-013-0349-1

Boehm, J., Werl, B. and Schuh, H.: 2006, Troposhere mapping functions for GPS and very long baseline interferometry from European Centre for MediumRange Weather Forecasts operational analysis data. J. Geophy. Res., 111, B02406. DOI: $10.1029 / 2005 J B 003629$

Bosy, J., Oruba, A., Graszka, W., Leończyk, M. and Ryczywolski, M.: 2008, ASG-EUPOS densification of EUREF Permanent Network on the territory of Poland. Rep. on Geodesy, 2, 85, 105-112.

Chatazinikos, M., Fotiou, A. and Pikradis, C.: 2009, The effects of the receiver and satellite antenna phase center models on local and regional GPS networks. Proceedings of the International Symposium "Modern technologies, educations and professional practice in geodesy and relative fields", Sofia, 5-6 November, 2009.

Dawidowicz, K., Krzan, G. and Świątek, K.: 2014, Urban area GPS positioning accuracy using ASG-EUPOS POZGEO service as a function of session duration.
Artificial Satellites, 49, 1, 33-42.

DOI: $10.2478 /$ arsa-2014-0003

Dawidowicz, K. and Krzan, G.: 2016, Analysis of PCC model dependent periodic signals in GLONASS position time series using Lomb-Scargle periodogram. Acta Geodyn. Geomater., 13, 3, 299-314. DOI: $10.13168 /$ AGG.2016.0012

Dawidowicz, K.: 2018, Differences in GPS coordinate time series caused by changing type-mean to individual antenna phase center calibration model. Stud. Geophys. Geod., 62, 38-56. DOI: $10.1007 / \mathrm{s} 11200-016-0630-1$

Dilssner, F., Springer, T., Schönemann, E. and Enderle, W.: 2016, Evaluating the pre-flight GPS Block IIR/IIR-M antenna phase pattern measurements. IGS Workshop, Sydney, Australia, February 11.

El-Mowafy, A.: 2011, Analysis of web-based GNSS postprocessing services for static and kinematic positioning using short data spans. Surv. Rev., 43, 323, 535-549. DOI: $10.1179 / 003962611 X 13117748892074$

Figurski, M.., Bogusz, J., Szafranek, K. and Kamiński, P.: 2010, Investigation on stability of mountainous EUPOS sites' coordinates. Acta Geodyn. Geomater., 7, 3, 263-274.

Figurski, M. and Nykiel, G.: 2017, Investigation of the impact of ITRF2014/IGS14 on the positions of the reference stations in Europe. Acta Geodyn. Geomater., 14, 43, 401-410. DOI: 10.13168/AGG.2017.0021

Görres, B., Campbell, M., Becker, M. and Sieme, M.: 2006, Absolute calibration of GPS antennas: Laboratory results and comparison with field and robot techniques. GPS Solut., 10, 136-145. DOI: $10.1007 / \mathrm{s} 10291-005-0015-3$

Hofmann-Wellenhof, B., Lichtenegger, H. and Collins, J.: 2001, GPS Theory and Practice, 5th, revised edition. Springer-Verlag, Wien New York.

Kersten, T. and Schön, S.: 2016, Receiver Antenna Phase Center Models and their impact on geodetic parameters. In: Freymueller, J.T. and Sánchez, L. (eds), International Symposium on Earth and Environmental Sciences for Future Generations. International Association of Geodesy Symposia, vol 147, 253-259. DOI: 10.1007/1345 2016 233

Kouba, J. and Héroux, P.: 2001, Precise Point Positioning using IGS orbit and clock products. GPS Solut., 5, 2, 12-28. DOI: 10.1007/PL00012883

Mader, G.L.: 1999, GPS Antenna calibration at the National Geodetic Survey. GPS Solut., 3, 1, 50-58. DOI: 10.1007/PL00012780

Meindl, M.: 2011, Combined analysis of observations from Different Global Navigation Satellite Systems. PhD thesis, Technische Hochschule Zürich, 150 pp. http://www.sgc.ethz.ch/sgc-volumes/sgk-83.pdf

Mohammed, J., Moore, T., Hill, C., Bingley, R.M. and Hansen, D.N.: 2016, An assessment of static precise point positioning using GPS only, GLONASS only, and GPS plus GLONASS. Measurement, 88, 121130. DOI: 10.1016/j.measurement.2016.03.048

Paziewski, J., Krukowska, M. and Wielgosz, P.: 2014, Preliminary results on performance of new ultrafast static positioning module - POZGEO-2 in areas outside the ASG-EUPOS network. Geodesy and Cartography, 63, 1, 101-109. DOI: $10.2478 /$ geocart-2014-0008 
Rebischung, P., Griffiths, J., Ray, J., Schmid, R., Collilieux, X. and Garayt, B.: 2011, IGS08: the IGS realization of ITRF2008. GPS Solut., 16, 4, 483-494. DOI: 10.1007/s10291-011-0248-2

Rebischung, P., Schmid, R. and Herring, T.: 2016, Upcoming switch to IGS14/igs14.atx. IGSMAIL7399 ,

https://lists.igs.org/pipermail/igsmail/2016/001233.html

Rebischung, P. and Schmid, R.: 2016, IGS14/igs14.atx: a new framework for the IGS products. Am. Geophys. Union, Fall Meeting 2016. https://www.researchgate.net/publication/311654495_IGS14i gs14atx_a new_framework_for_the IGS products

Rizos, Ch., Janssen, V., Roberts, C. and Grinter, T.: 2012, Precise Point Positioning: Is the era of Differential GNSS Positioning Drawing to an end? In: FIG Working Week 2012, Rome, Italy.

Rothacher, M. and Mader, G.: 1996, Combination of antenna phase center offsets and variation: antenna calibration set IGS_01, anonymous ftp ubeclu.unibe.ch, June.

Schmid, R., Steingerberg, P., Gendt, G., Ge, M. and Rotchacher, M.: 2007, Generation of a consistent absolute phase center corrections model for GPS receiver and satellite antennas. J. Geodesy, 81, 12, 781-798. DOI: 10.1007/s00190-007-0148-y

Sidorov, D. and Teferle, F.N.: 2013, Antenna Phase Centre Calibration effects on Position Time-Series: Preliminary Results. IAG Scientific Assembly, IAG 150 Years, Potsdam, Germany, September 1-6.

Springer, T.A.: 2009, NAPEOS - Mathematical models and algorithms. Technical note, DOPS-SYS-TN-0100OPS-GN， ftp://dgn6.esoc.esa.int/napeos/DOPS-SYSTN-0100-OPS-GN-MathModels.pdf.

Stępniak, K., Wielgosz, P. and Baryła, R.: 2015, Field tests of L1 phase centre variation models of surveyinggrade GPS antennas. Stud. Geophys. Geod., 59, 394408. DOI: $10.1007 / \mathrm{s} 11200-014-0250-6$

Schön, S. and Kersten, T.: 2014, Comparing antenna phase center corrections: challenges, concepts and perspectives. IGS Analysis Workshop, Pasadena, California, June 23 - 27, https://www.ife.unihannover.de/uploads/tx tkpublikationen/IGS2014 sch oenKersten.pdf.
Völksen, Ch.: 2006, The Impact of different GPS Antenna Calibration Models on the EUREF Permanent Network. Report on the Symposium of the IAG Subcommission for Europe (EUREF), Mitteilungen des BKG, Frankfurt/Main, 73-78.

Wübbena, G., Menge, F., Schmitz, M., Seeber, G. and Völksen, Ch.: 1996, A new approach for field calibration of Absolute Antenna Phase Center variations. ION GPS-96, Kansas City, Missouri. September 1996, 1205-1214.

Wübbena, G., Schmitz, M., Boettcher, G. and Schumann, Ch.: 2006, Absolute GNSS antenna calibration with a robot: Repeatability of phase variations, calibration of GLONASS and determination of carrier-to-noise pattern. Proceedings of the IGS Workshop: Perspectives and Visions for 2010 and beyond, 8-12 May, Darmstadt, Germany.

Yigit, C.O., Gikas, V., Alcay, S. and Ceylan, A.: 2013, Performance evaluation of short to long term GPS, GLONASS and GPS/GLONASS post-processed PPP. Surv. Rev., 46, 336, 155-166. DOI: $10.1179 / 1752270613$ Y.0000000068

Zeimetz, P. and Kuhlman, H.: 2008, On the accuracy of absolute GNSS antenna calibration and the conception of a new anechoic chamber. FIG Working Week 2008, Stockholm, Sweden 14-19 June.

Zhu, S.Y., Massmann, F.H., Yu,Y. and Reigber, Ch.: 2003, Satellite antenna phase center offsets and scale errors in GPS solutions. J. Geodesy, 77, 11-12, 668-672. DOI: $10.1007 / \mathrm{s} 00190-002-0294-1$ 